\title{
The end-bearing capacity of piles penetrating into crushable soils
}

\author{
C. ZHANG*, G. D. NGUYEN* and I. EINAV*
}

\begin{abstract}
A new formula is proposed for the end-bearing capacity of piles penetrating into crushable soils. The formula is based on a breakage mechanics model that accounts for the evolution of the grain size distribution (GSD) due to grain crushing with only physically meaningful parameters. The model is integrated using the finite-element method to study the penetration problem. Predictions of GSDs surrounding piles and pile end-bearing capacities are validated against experiments. Next, a parametric study is carried out to quantify the effects of grain crushing on the bearing capacity, and then to establish the formula. The predictive capability of the new formula is highlighted against predictions by previous formulae, which highlights its superior origins.
\end{abstract}

KEYWORDS: bearing capacity; constitutive relations; numerical modelling; particle crushing/crushability; piles

\section{INTRODUCTION}

Conventional bearing capacity equations predict increasing resistance with increasing friction angle (e.g. Terzaghi, 1943). Accordingly, given the relatively high friction angle of calcareous sand, it can be expected that its resistance against pile penetration would be high. However, in such crushable soils the bearing capacity is much lower than expected from the conventional equations (Poulos \& Chua, 1985; Golightly \& Hyde, 1988; Yu, 2000; Yamamoto et al., 2009). For example, it has been shown experimentally that for comparable tip resistances, pile displacements in highly crushable materials are much larger than in non-crushable soils (Kuwajima et al., 2009). This is because grain crushing helps the soil to accommodate the new volumetric intrusion by the pile. The result is an overall reduction of the total volume, defined by the soil compressibility. In crushable sands, the compressibility is governed by the way the GSD evolves, as observed experimentally (Datta et al., 1979) and rationalised theoretically (Einav, 2007a). The GSD influences the strength and stress-strain behaviour of the soil (Hardin, 1985; Lade et al., 1996), and subsequently affects the end-bearing capacity of the pile. For example, using geotechnical centrifuge tests of a model pile driven into crushable soils, McDowell \& Bolton (2000) noticed that the resistance to penetration by well-graded soils is higher than that by uniformly poorly graded soils.

The importance of soil crushability for the design and construction of pile foundations was highlighted from a practical standpoint (Datta et al., 1980; Poulos \& Chua, 1985; Alba \& Audibert, 1999). Various laboratory and in situ field tests (e.g. pile load test, cone penetration test (CPT), and pressuremeter test (PMT)) have been carried out to obtain relevant experimental information and determine pile end-bearing capacities (Foray et al., 1999; Joer et al., 1999). Simple models of cavity expansion were also used to assess end-bearing capacities, and Vesic (1973b) has used this approach to derive an end-bearing capacity equation for piles dependent on the confining pressure and soil compressibility. The applicability of his derived formula has been noted for both shallow footings (Poulos, 1989) and piles (Yasufuku \& Hyde, 1995) residing in crushable soils, at least

Manuscript received 14 September 2011; revised manuscript accepted 18 July 2012. Published online ahead of print 29 October 2012. Discussion on this paper closes on 1 September 2013, for further details see p. ii.

* School of Civil Engineering, University of Sydney, Australia. when compared with results yielded by Terzaghi's original equation (Terzaghi, 1943). The outcome, however, does not explain why the bearing capacity varies with crushability and variations in the GSDs. Another formula relating the end-bearing capacity to the cavity expansion pressure was developed by Yasufuku \& Hyde (1995). Their proposed equation requires the introduction of a so-called 'secant friction angle' in order to capture the observed pressure dependence of the end-bearing capacity; the secant friction angle is not a fundamental soil property, however, and therefore cannot explain why the bearing capacity varies with crushability and GSDs. More recently Russell \& Khalili (2002) employed the cavity expansion approach to study the effect of grain crushing on CPT and PMT model tests, which required an assumed relation between the grain crushing and the compressibility by way of the void ratio, but this relation was empirical, and thus cannot respond to variation in the tested material and its initial GSD.

The purpose of this paper is to establish a more complete, rigorous and reliable bearing capacity equation for piles penetrating into sand that considers the grain crushability as well as other critical factors (e.g. GSD, friction coefficient, and elastic stiffness). To achieve this purpose the problem is analysed using the micromechanics-based continuum theory of breakage mechanics (Einav, 2007a, 2007b, 2007c, 2007d). This theory rigorously takes into account the effects of the evolving cumulative GSD due to grain crushing on the material behaviour by incorporating an internal breakage variable $B$ within the framework of thermodynamics. Here a simple constitutive model of breakage mechanics is implemented (the so-called 'student model' of breakage mechanics, as proposed by Einav (2007d)) into the finite-element method (FEM). This FEM model is defined to represent a pile penetrating into crushable soils, which thus enables us to capture failures dependent on both grain crushing and friction. Also, given the ability to find $B$ anywhere in space and time, the model can also track the evolution of the GSDs surrounding the pile during its penetration. Comparing with experiments, it is shown that the FEM model predicts well the pile end-bearing capacities, evolving GSDs and soil deformations. On this basis a parametric study is then carried out to establish the new formula for the end-bearing capacity of piles. The formula is robust and versatile, and can capture the effects of variability of many physical parameters, including the pressure, the initial GSD, the critical comminution pressure that defines the onset of 
yielding, the friction coefficient and the elastic stiffness of the material. A brief discussion on the role of the initial density (through porosity) will also be provided.

It is important to acknowledge previous works that implicitly introduce the effects of grain crushing into constitutive models (Daouadji et al., 2001; Muir Wood \& Maeda, 2007; Daouadji \& Hicher, 2009), typically by extending the criticalstate framework of plasticity. Although these contributions emphasise the need to link stress-strain relations to grain crushing, they have done this without considering thermodynamic admissibility, and have missed the kinematics linked to the creation of surface area (i.e. missed aspects of strain evolution) and its conjugated energetics (i.e. missed aspects of stress evolution). The GSD in these works was therefore not an independent state variable, and thus those models rely on heavy use of complex experimental programmes for curve-fitting breakage to pressure (notice, however, that the relation between breakage and pressure is physically pathdependent). Distinguished from these works, here the model is thermodynamically admissible; it is physically pathdependent; and it embodies the balance between the kinetics of surface creation and the energy required for surface alterations in confined granular materials (Einav, 2007c).

\section{A CONSTITUTIVE MODEL BASED ON BREAKAGE MECHANICS THEORY}

The cumulative GSD (sieve curve) is one of the most widely measured properties in soil mechanics and geotechnical engineering. Its importance in governing the mechanical response of soils has been well acknowledged (Lade et al., 1996; McDowell \& Bolton, 2000). However, only recently this property was consistently considered to formulate constitutive models, through the breakage mechanics theory of Einav (2007a, 2007b). In this theory a micromechanics-based internal variable, called breakage, $B$, was introduced in a way that makes it possible to predict the evolving GSD. The explicit connection between the micromechanics of grain crushing and macroscopic model behaviour means that better prediction of mechanical response is achieved with fewer physically identifiable model parameters. Consequently, experimental observations are better explained and new phenomena predicted, such as the permeability reduction in such soils (Nguyen \& Einav, 2009, Zhang et al., 2010). In the following, first a few key points of breakage mechanics theory are listed, followed by a brief explanation of the simple 'student model' of breakage mechanics. Readers are referred to earlier works by Einav (2007a, 2007b, 2007c, 2007d) for a description of this theory and the simplest student model.

The problems in this paper depend on complexity arising from two different sources: material complexity determined by the constitutive model, and geometrical complexity determined by the boundary conditions imposed in the FEM. In the authors' opinion, it is not instructive to include all the complexity at once. This is the first reason why the linear elastic breakage model is used in this paper. The second reason is the authors' intention to derive formulae based on a limited number of parameters, which could be readily understood by any practical engineer. Of course, material complexity could be captured with more advanced breakage models. For example, Nguyen \& Einav (2009) showed how pressure-dependent Hertzian elasticity could be incorporated into the formulation, and how this improves stress-strain predictions. Furthermore, the use of porosity is also not introduced directly in the current analysis, but Rubin \& Einav (2011) solved this issue in the context of breakage mechanics. Finally, notice that the breakage variable, $B$, only weighs the proximity of the current GSD to the initial and ultimate GSDs. Certainly, using a single evolutionary scalar variable $(B)$ to replace an evolutionary function (the GSD) is a simplification: for example, after shear path or compression path, $B$ might be the same, but the GSDs could be different. The practical advantages of employing this 'fractional breakage' hypothesis have been highlighted by Einav (2007a), as a viable first step before refining the model.

In short, although the breakage model used in this paper is the simplest available, in the authors' view this is practically justifiable, since the boundary conditions of the analysed problem are sufficiently complex. The integrated effect of assembling the contributions from all the various points in space is therefore as important as capturing accurately the constitutive behaviour of each of these points. This is the same reason why rigorous FEM analyses with simple constitutive models (e.g. Tresca, Mohr-Coulomb and Cam Clay elasto-plasticity) can still be relevant.

\section{Breakage mechanics theory: key points}

The rigour and novelty of the breakage mechanics theory for crushable soils can be attributed to several key points. There are five key points relevant to the current paper, as highlighted below (Einav, 2007a).

(a) Breakage, $B$, is introduced to predict the current cumulative GSD by mass $(F(x, B))$ through a linear scaling between the initial $\left(F_{0}(x)\right)$ and ultimate cumulative GSDs $\left(F_{\mathrm{u}}(x)\right)$.

$$
F(x, B)=(1-B) F_{0}(x)+B F_{\mathrm{u}}(x)
$$

(b) The ultimate GSD, $F_{\mathrm{u}}(x)$, is associated with the critical state. In the current model this is done without incorporating effects of dilation as a competing phenomenon to grain crushing in low stresses. However, as modelled by Rubin \& Einav (2011), introducing such an effect into the breakage formulation helps to highlight the role of this competition in determining the non-uniqueness of the critical-state pressure-porosity relation in sand (evidenced experimentally, e.g. by Coop et al. (2004)). Although not absolutely necessary, it is practical to employ a fractal power law $F_{\mathrm{u}}(x)$ (Sammis et al., 1986; McDowell et al., 1996; Ben-Nun \& Einav, 2010). Notice, however, that although the model associates $F_{\mathrm{u}}(x)$ with the critical state, this does not mean that this ultimate grading should always be reached after the pile has penetrated, thanks to the elastic rebound after the material points have passed the pile's tip.

(c) The specific elastic strain energy stored in larger grains is greater than in smaller grains. To a first order this energy scales with the grains' surface area. This assumption was verified by Einav (2007a), using the discrete-element method under isotropic loading conditions, and by BenNun (2010) under cavity expansion, simple shear, and biaxial test conditions. The basic reason for this (apparently) universal finding is that larger grains carry more contacts in proportion to their larger surface.

(d) Through statistical homogenisation, the macroscopic specific elastic strain energy stored is the average of such energies stored in the various size fractions, determined by the current GSD, $F(x, B)$.

(e) Breakage dissipation from grain crushing is equal to the loss in the residual breakage energy (the residual breakage energy reflects the energy left in the system to crush particles towards the ultimate GSD, $\left.F_{\mathrm{u}}(x)\right)$.

\section{Constitutive equations of the simple breakage model}

In the student model of breakage mechanics, the stored elastic energy of a unit volume of idealised monodispersed 
material made of particles with a reference grain size is simplified by adopting linear elasticity (Einav, 2007d). This, in addition to key points (a)-(d), provides macroscopic specific elastic strain energy for the polydispersed material with crushable grains in the form

$$
\Psi=(1-\vartheta B)\left(\frac{1}{2} K \varepsilon_{\mathrm{v}}^{\mathrm{e} 2}+\frac{3}{2} G \varepsilon_{\mathrm{s}}^{\mathrm{e} 2}\right)
$$

where $K$ and $G$ are the bulk and shear moduli, and $\varepsilon_{\mathrm{v}}^{\mathrm{e}}$ and $\varepsilon_{\mathrm{s}}^{\mathrm{e}}$ are the elastic volumetric and shear strains in triaxial conditions. In addition to these mechanical parameters, this energy depends on a physical grading index $\vartheta$. This property is a rigorous trace of the statistical homogenisation (key point (d)), which weights the relative proximity of the initial cumulative GSD to the ultimate one using their second-order moments (Einav, 2007b).

Employing the framework of thermodynamics, constitutive relations can be defined for the mean (effective) stress $p$, the triaxial shear stress $q$, and the stress-like conjugate to the breakage, called the breakage energy, $E_{\mathrm{B}}$.

$$
\begin{aligned}
& p=\frac{\partial \Psi}{\partial \varepsilon_{\mathrm{v}}^{\mathrm{e}}}=(1-\vartheta B) K \varepsilon_{\mathrm{v}}^{\mathrm{e}} \\
& q=\frac{\partial \Psi}{\partial \varepsilon_{\mathrm{s}}^{\mathrm{e}}}=3(1-\vartheta B) G \varepsilon_{\mathrm{s}}^{\mathrm{e}} \\
& E_{\mathrm{B}}=-\frac{\partial \Psi}{\partial B}=\frac{\vartheta}{2}\left(K \varepsilon_{\mathrm{v}}^{\mathrm{e} 2}+3 G \varepsilon_{\mathrm{s}}^{\mathrm{e} 2}\right)
\end{aligned}
$$

As a consequence of the energy balance stated by key point (e), and by further assuming a Mohr-Coulomb failure criterion, a yield function can be expressed in the mixed space of all the above three stresses (Einav, 2007c, 2007d) as

$$
y=\frac{E_{\mathrm{B}}}{E_{\mathrm{c}}}(1-B)^{2}+\left(\frac{q}{M p}\right)^{2}-1 \leqslant 0
$$

where $E_{\mathrm{c}}$ is the critical breakage energy (with the dimension of stress); $M=q_{\mathrm{f}} / p_{\mathrm{f}}$ defines the friction ratio at critical state between the ultimate mean and triaxial shear stresses, $p_{\mathrm{f}}$ and $q_{\mathrm{f}}$ respectively. Using equations (3), (4) and (5), the yield condition can be rewritten in terms of triaxial stresses as

$$
y=\frac{\vartheta}{2 E_{\mathrm{c}}}\left(\frac{p^{2}}{K}+\frac{q^{2}}{3 G}\right)\left(\frac{1-B}{1-\vartheta B}\right)^{2}+\left(\frac{q}{M p}\right)^{2}-1 \leqslant 0
$$

An example of the yield surface in $p-q-B$ space is plotted in Fig. 1 for representative parameters.

The flow rules to the yield are defined in a way that does not violate the second law of thermodynamics, with the mechanical dissipation ensured to be non-negative. Consequently, the flow rules are defined as non-associated (see Einav (2007b) and Nguyen \& Einav (2009) for details), with strong coupling imposed between breakage and plastic strains (Einav, 2007b) as follows.

$$
\delta \varepsilon_{\mathrm{v}}^{\mathrm{p}}=\delta \lambda \frac{2 E_{\mathrm{B}}(1-B)^{2} \sin ^{2} \omega}{p E_{\mathrm{c}}}
$$

$$
\begin{aligned}
& \delta \varepsilon_{\mathrm{s}}^{\mathrm{p}}=\delta \lambda \frac{2 q}{(M p)^{2}} \\
& \delta B=\delta \lambda \frac{2(1-B)^{2} \cos ^{2} \omega}{E_{\mathrm{c}}}
\end{aligned}
$$

where $\delta \lambda$ is a non-negative multiplier; $\delta \varepsilon_{\mathrm{v}}^{\mathrm{p}}$ and $\delta \varepsilon_{\mathrm{s}}^{\mathrm{p}}$ define the incremental plastic volumetric and shear strains respectively; $\delta B$ is the incremental breakage, which highlights key point (a) of breakage mechanics, allowing one to track the evolution of the current GSD (see equation (1)); and the angle $\omega$ governs the coupling between plastic volumetric strain dissipation and grain crushing dissipation. Values of $\omega=0^{\circ}$ and $\omega=90^{\circ}$ represent two extremes corresponding to dissipative processes due to grain crushing only and plastic volumetric strain only. Phenomenologically, $\omega$ affects the flow rule in equations (8) and (9), and thus the model could be thought to be non-associated in the conventional sense. However, the model was derived based on thermodynamics, and depends on an additional stress conjugated to the breakage flow, the breakage energy $E_{\mathrm{B}}$. In this sense the model is associated with a dissipative $E_{\mathrm{B}}-p-q$ stress space. However, $\omega$ has physical meaning linked to local pore collapse, and increases with the quantity of internal pores within the grains (see discussion by Das et al. (2011)).

The above model possesses only five physically identifiable mechanical parameters: the shear and bulk moduli $G$ and $K$, the friction coefficient $M$, the critical breakage energy $E_{\mathrm{c}}$, and the coupling angle $\omega$ between the friction and breakage dissipative processes. All of these parameters can be measured and calibrated from a single standard triaxial test involving a stage of isotropic compression followed by a stage of drained or undrained shear. In addition, the model responds to variations in the initial GSD through the grading index $\vartheta$. It will be shown later that the bearing capacity is sensitive only to four mechanical parameters, without much effect from $\omega$. The energy threshold $E_{\mathrm{c}}$ is calculated from the maximum yield pressure defining the yield surface, the so-called 'critical comminution pressure', $p_{\mathrm{c}}$, which marks the commencement of grain crushing during isotropic compression (Einav, 2007c)

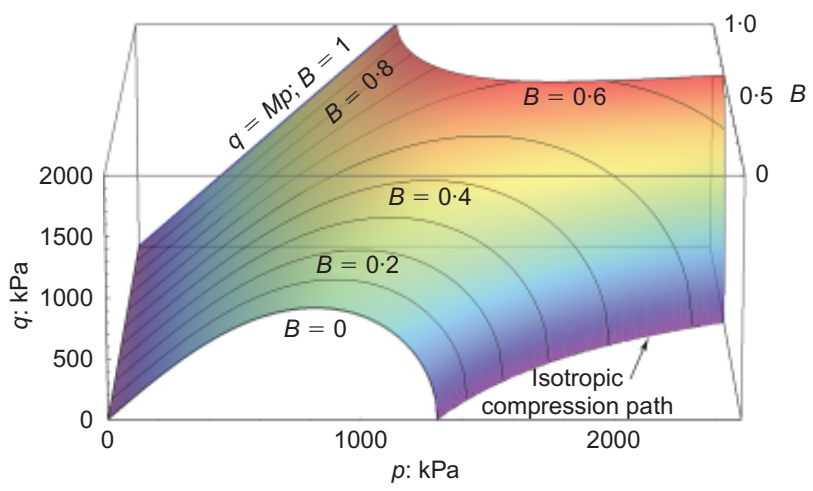

Fig. 1. Yield surface in $p-q-B$ space (Dog's Bay sand parameters, as listed in Table 1)

Table 1. Model parameters for crushable sand

\begin{tabular}{l|c|c|c|c|c|c}
\hline Sand & $K: \mathrm{MPa}$ & $G: \mathrm{MPa}$ & $p_{\mathrm{c}}: \mathrm{MPa}$ & $M$ & $\omega:$ degrees & $\vartheta$ \\
\hline Fontainebleau sand & $28 \cdot 3$ & $13 \cdot 1$ & $23 \cdot 0$ & $1 \cdot 50$ & 55 & $0 \cdot 70$ \\
Chiibishi sand & $17 \cdot 8$ & $14 \cdot 5$ & $1 \cdot 3$ & $1 \cdot 77$ & 30 & $0 \cdot 20$ \\
Dog's Bay sand & $25 \cdot 0$ & $14 \cdot 0$ & $0 \cdot 6$ & $1 \cdot 65$ & 38 & $0 \cdot 65$ \\
\hline
\end{tabular}




$$
p_{\mathrm{c}}=\sqrt{\frac{2 K E_{\mathrm{c}}}{\vartheta}}
$$

The implementation of the above model in finite-element code is presented in Appendix 1.

The above model does not reflect the dependence of the soil behaviour on density, and does not directly reflect the recent finding by Altuhafi \& Coop (2011) that the relation between breakage and pressure (e.g. as shown in Fig. 1) also depends on the porosity. However, more recently, such effects were explained by Rubin \& Einav (2011), within the thermodynamics framework of breakage mechanics. Their work showed that by taking the porosity-dependent bulk modulus, in a form similar to that proposed by Hardin \& Black (1966) and Viggiani \& Atkinson (1995), the critical comminution pressure could be approximated by a linear dependence on the solid fraction

$$
p_{\mathrm{c}} \approx\left(1-n_{0}\right) \sqrt{\frac{2 K E_{\mathrm{c}}}{\vartheta}}
$$

where $n_{0}$ is the initial porosity.

\section{Model predictions}

The constitutive behaviour of two typical calcareous soils, Dog's Bay and Chiibishi sands, are numerically predicted using the above breakage model under drained triaxial shear tests at different initial confining pressures. The model parameters listed in Table 1 correspond to measured data from Kuwajima et al. (2009) and Coop et al. (2004). The index property $\vartheta$ for Dog's Bay sand can be calculated based on the initial and ultimate cumulative GSDs, and that for Chiibishi sand is determined from the experimentally given initial cumulative GSD and an assumed distribution for the ultimate cumulative GSD of the following fractal form with a maximum and a minimum cap (e.g. Einav, 2007a).

$$
F_{\mathrm{u}}(x)=\frac{x^{3-\alpha}-D_{\mathrm{m}}^{3-\alpha}}{D_{\mathrm{M}}^{3-\alpha}-D_{\mathrm{m}}^{3-\alpha}}
$$

where $D_{\mathrm{m}}$ and $D_{\mathrm{M}}$ are the minimum and maximum size of the grains, and the fractal dimension $\alpha$ takes the value $\alpha=2 \cdot 7$ (Turcotte, 1986; Coop et al., 2004). Figs 2 and 3 show the corresponding agreement between numerical predictions and experimental observations.

\section{ANALYSIS OF CONE-ENDED MODEL PILE TEST}

Yang et al. (2010) carried out a cone-ended model pile test in a quartz Fontainebleau sand, under an initial vertical stress of $150 \mathrm{kPa}$. They measured the pile's resistance and the crushing profile surrounding the driven pile, which will be used to validate the numerical results in this study. The numerical simulation is conducted by employing the arbitrary Lagrangian Eulerian (ALE) method, where appropriate remeshing and variable remapping are used for large deformation analysis (Abaqus, 2007).

The axis-symmetric finite-element model is depicted in Fig. 4(a), including the boundary conditions, the overall model dimensions based on Yang et al. (2010), and the mesh discretisation. The preparation of the finite-element sample involves three stages that represent the experimental set-up: a first stage where gravity is applied gradually; a second stage where a top pressure of $150 \mathrm{kPa}$ is gradually applied to the surface of the model; and a third and last stage where the pile is driven into the modelled sand using the ALE technique. It was found that at the end of the second stage none of the material points in the finite-element model was

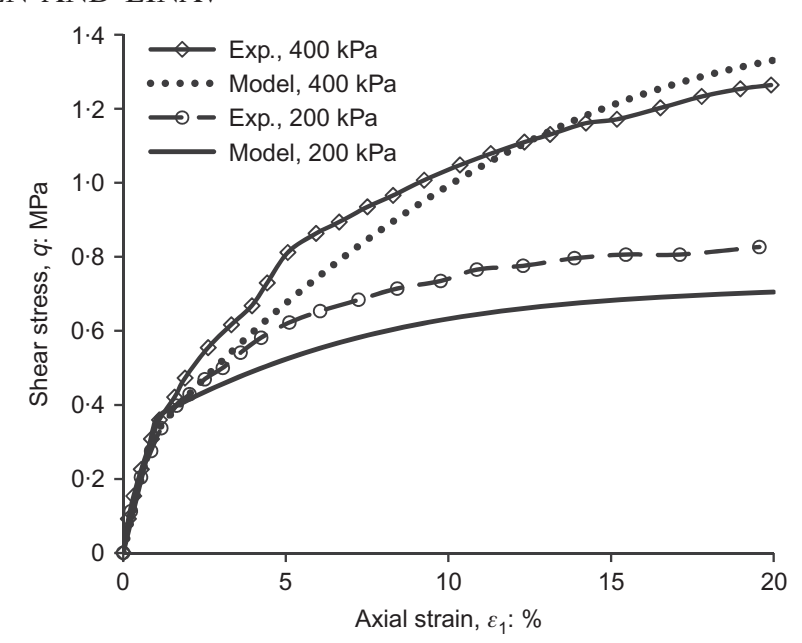

(a)

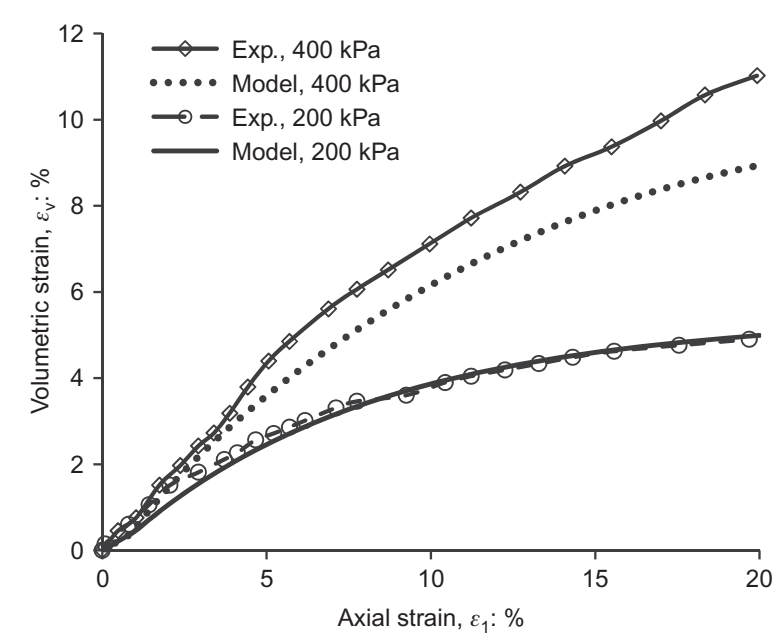

(b)

Fig. 2. Model predictions of mechanical response of Dog's Bay sand under drained triaxial shear tests at different initial confining pressures: (a) shear stress against axial strain; (b) volumetric strain against axial strain (experimental data from Kuwajima et al., 2009)

actually yielding, and the state was purely elastic and could be matched by an elastic $K_{0}$ condition. Therefore it is actually possible to start the analysis directly from the third stage, and using $K_{0}=v /(1-v)$ ( $v$ being Poisson's ratio) to establish the horizontal stresses using the known vertical effective stresses.

The current analysis is based on parameters from De Gennaro \& Frank (2002): $v=0 \cdot 3, \quad K=28 \cdot 3 \mathrm{MPa}$ and $G=13 \cdot 1 \mathrm{MPa}$ for stresses of the order of $100 \mathrm{kPa}$ (as in the current analysis), based on a series of triaxial experiments on quartz Fontainebleau sand. As indicated above, the initial stresses at the beginning of the penetration analysis correspond to an elastic solution with lateral earth coefficient $K_{0}=0.43$ (corresponding to $v=0 \cdot 3$ ). Furthermore, still following De Gennaro \& Frank (2002) the friction coefficient is taken as $M=1.5$ (based on an effective friction angle of $\phi=36 \cdot 5^{\circ}$ ). The predictions in this paper are based on these parameters, and without any adjustment, a fact that highlights the model's capabilities.

Other parameters are from Yang et al. (2010): the soilpile interface friction coefficient $\mu=\tan \left(\phi_{p}\right)$ was calculated using the measured interface friction angle $\phi_{\mathrm{p}}=25^{\circ}$, the (effective) unit weight of sand $\gamma=16.3 \mathrm{kN} / \mathrm{m}^{3}$, and the critical comminution pressure $p_{\mathrm{c}}=23 \mathrm{MPa}$ was taken from a one-dimensional compression test (where the initial yield 


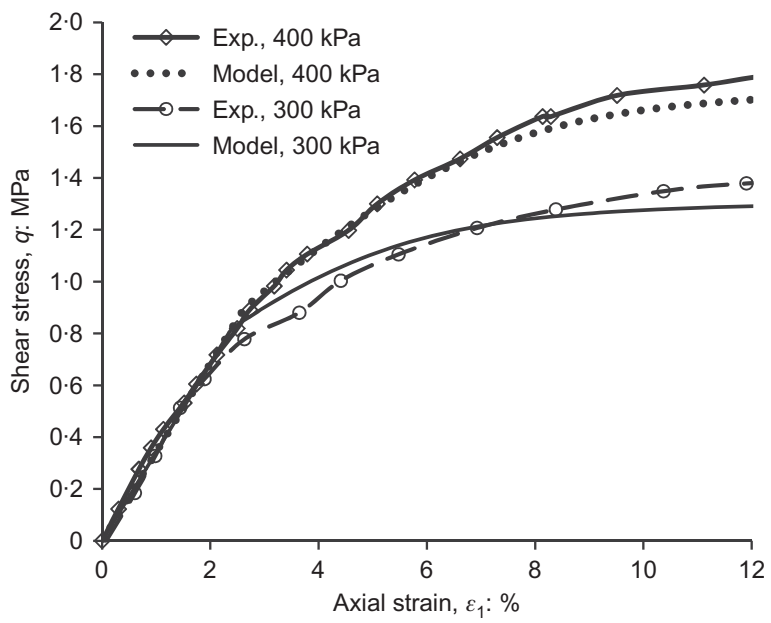

(a)

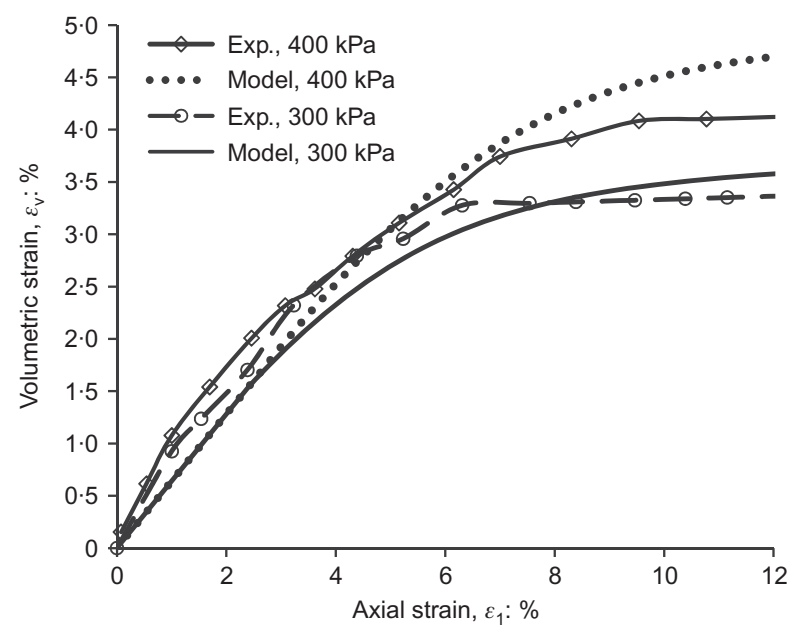

(b)

Fig. 3. Model predictions of mechanical response of Chiibishi sand under drained triaxial shear tests at different initial confining pressures: (a) shear stress against axial strain; (b) volumetric strain against axial strain (experimental data from Kuwajima et al., 2009) pressure was taken from the maximum curvature of the compression line in $e-\log \sigma_{\mathrm{v}}$ space, and $K_{0}$ was used to convert the stress yield point $\sigma_{\mathrm{vc}}$ to $\left.p_{\mathrm{c}}=\sigma_{\mathrm{vc}}\left(1+2 K_{0}\right) / 3\right)$. In addition, based on the initial GSD in Yang et al. (2010), the grading index is taken as $\vartheta=0.7$ (following Einav (2007b)), where the ultimate cumulative GSD was assumed to follow a fractal grading with a fractal dimension $\alpha=2 \cdot 7$. The agreement between the theory and the experiment is excellent when the plastic breakage coupling angle $\omega$ is $55^{\circ}$. The parameters used are summarised in Table 1.

The crushing profiles corresponding to different penetration depths are depicted in Figs 4(b)-4(d), showing that the crushing-influenced zone is within approximately half a pile radius from the shaft, in agreement with the experimental observation (Yang et al., 2010). A closer view is given in Fig. 5, where the numerically predicted breakage isolines are plotted in Fig. 5(b) and the experimental ones in Fig. 5(a). The predicted cumulative GSD can be determined from the breakage using the initial and ultimate cumulative GSDs (equation (1)), and this is compared with the experimental measurements in Figs 6(a)-6(c). Fig. 6(d) presents the theoretical prediction for the breakage variable $B$, which is plotted against the measured values calculated by the breakage definition (Einav, 2007a). Note that the data collated from zone 1 refer to many crushed sand samples at different depths, whereas only two samples were used to estimate the GSD in zone 2 (Yang et al., 2010). This indicates that the experimental cumulative GSD is more reliable in zone 1 than in zone 2. Overall, the FEM model predicts the evolving GSD remarkably well in all three zones (Figs 6(a)$6(d)$ ). The numerically predicted end-bearing capacity of the model pile with penetration depth also compares well with its experimental counterpart (Fig. 7). The small noise shown by the numerical solution is linked directly to the remeshing cycles in the Abaqus calculation, as part of the ALE method.

\section{ANALYSIS OF PILE PENETRATION}

In this section, the breakage constitutive model is used in a Eulerian finite-element framework to study a flat-ended

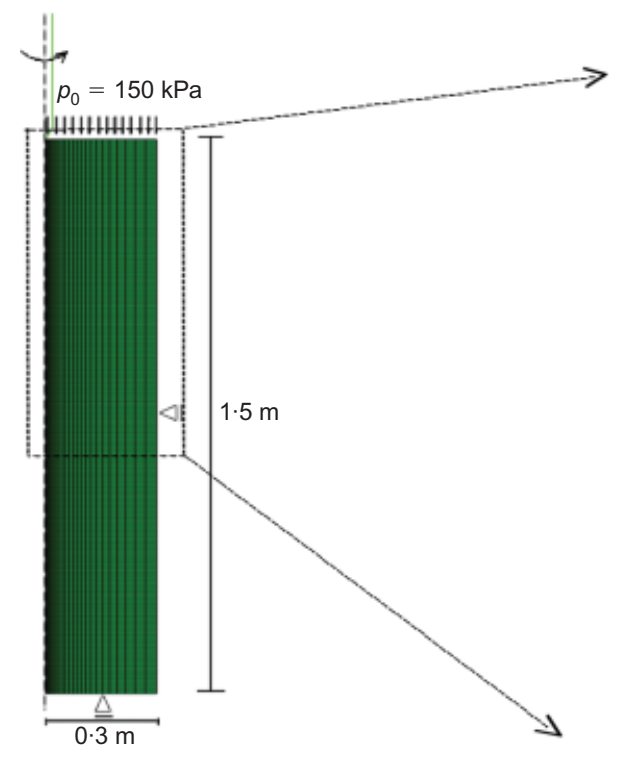

(a)

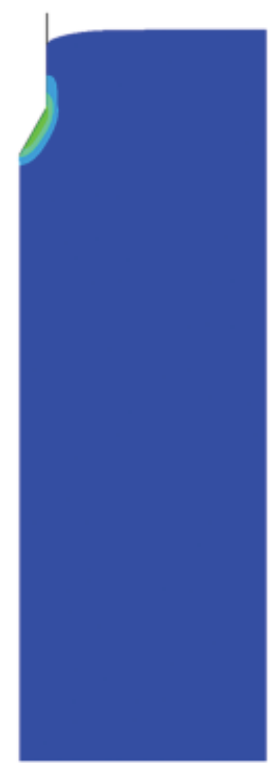

(b)

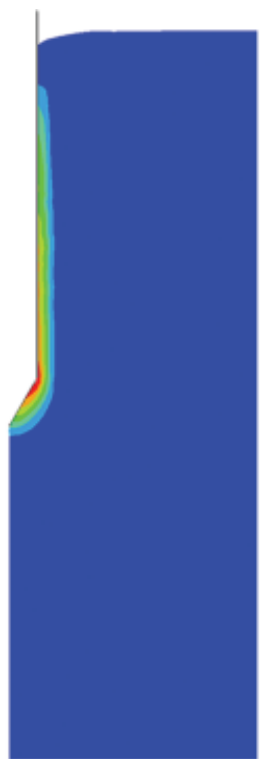

(c)

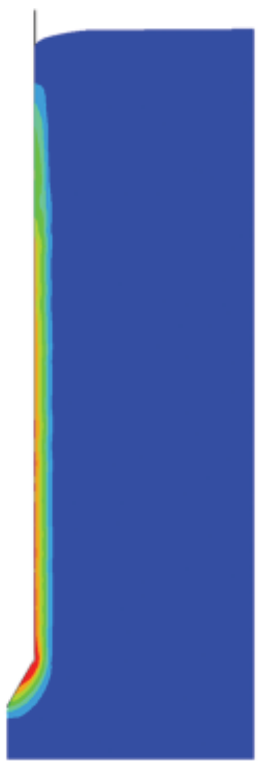

(d)

Fig. 4. Simulation of model pile test in Fontainebleau sand: (a) finite-element mesh and boundary conditions: (b)-(d) breakage distributions corresponding to penetration depths of $S=5 r, S=15 r, S=25 r$ respectively ( $S$, penetration depth; $r$, pile radius) 


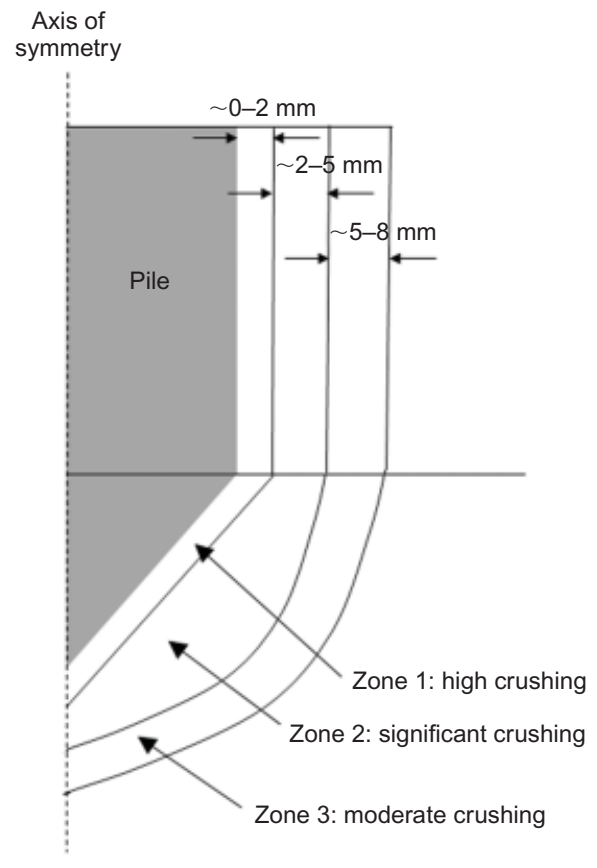

(a)

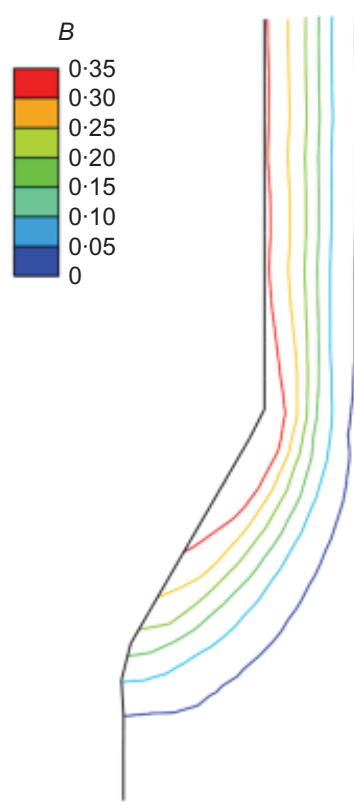

(b)

Fig. 5. Simulation of model pile test in Fontainebleau sand, profile of crushing zones: (a) experimental (reproduced from Yang et al., 2010); (b) numerical

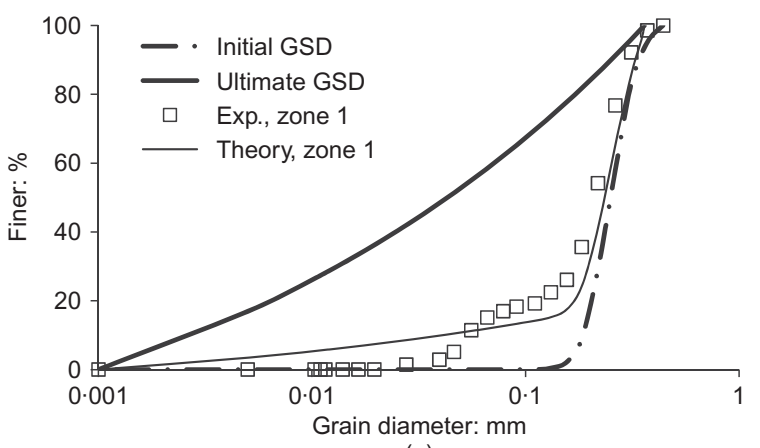

(a)

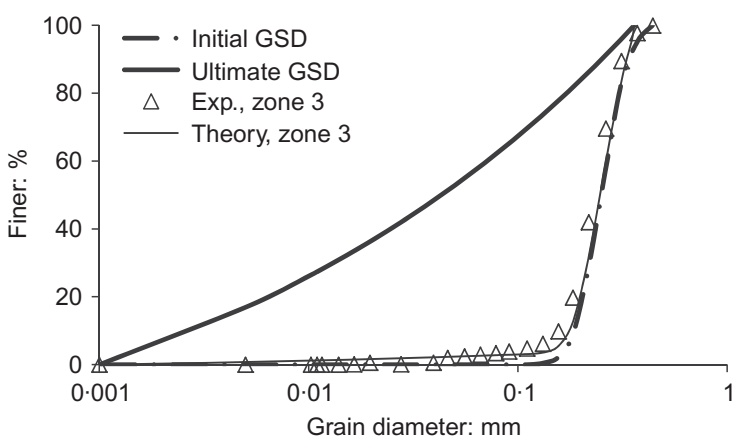

(c)

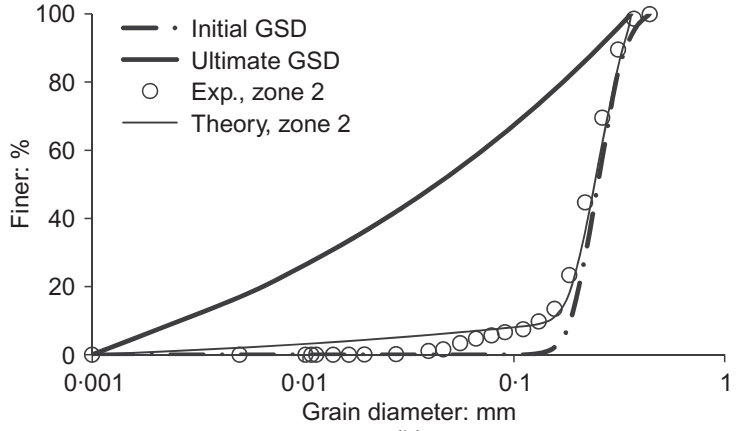

(b)

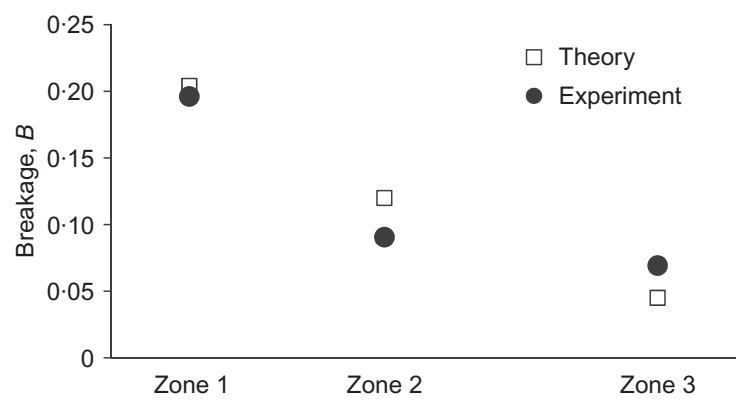

(d)

Fig. 6. Simulation of model pile test in Fontainebleau sand. Average grain size distributions for (a) zone 1, (b) zone 2, (c) zone 3; (d) average breakage index for zones 1, 2 and 3 indicated in Fig. 5(a)

cylindrical pile penetrating into a crushable sand, Chiibishi sand (Kuwajima et al., 2009). This axis-symmetric FEM model is intended to overcome the large distortion issues associated with the ALE or updated Lagrangian method for piles with high cone angles such as $90^{\circ}$ in flat-tip piles (Sheng et al., 2005). An appropriate discretisation was selected after a check was made to confirm that the results converge upon mesh refinement (Zhang et al., 2010). The model and boundaries are illustrated in Fig. 8, in which only part of the pile, with length $L=4 \mathrm{~m}$, is simulated. As indicated in the figure, the lateral walls prevent horizontal movements; the pile's tip prevents vertical movement; and the top and bottom walls maintain constant vertical stress $\sigma_{\mathrm{v} 0}$, and enable the inflow and outflow of mass fluxes at a constant rate reflecting the pile's penetration velocity. The material properties are listed in Table 1 (based on the calibration in the section 'Model predictions' above). Note that the initial stresses are pre-established in current analyses 


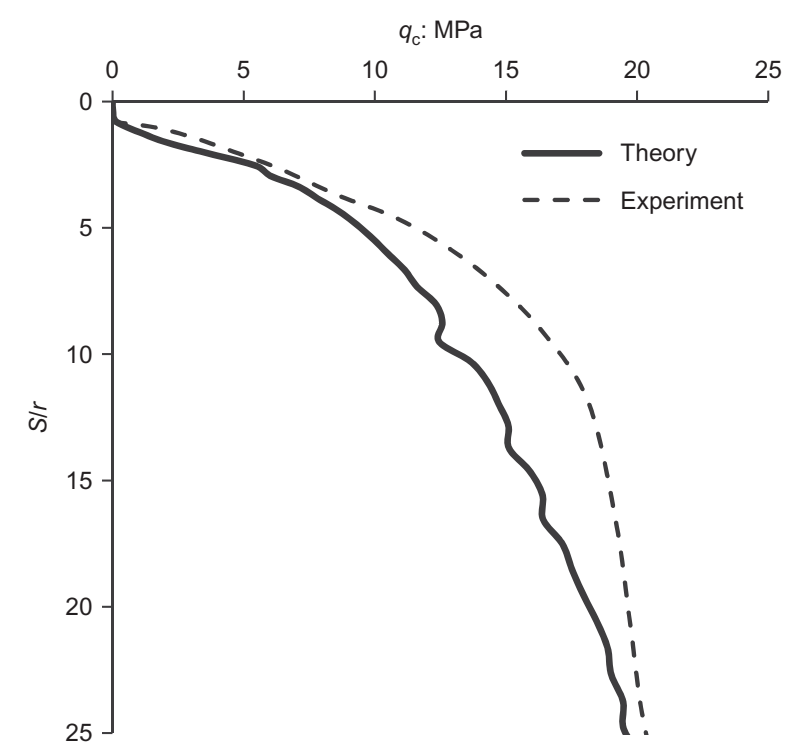

Fig. 7. Simulation of model pile test in Fontainebleau sand: endbearing capacity $q_{\mathrm{c}}$ against normalised penetration depth $S / r$

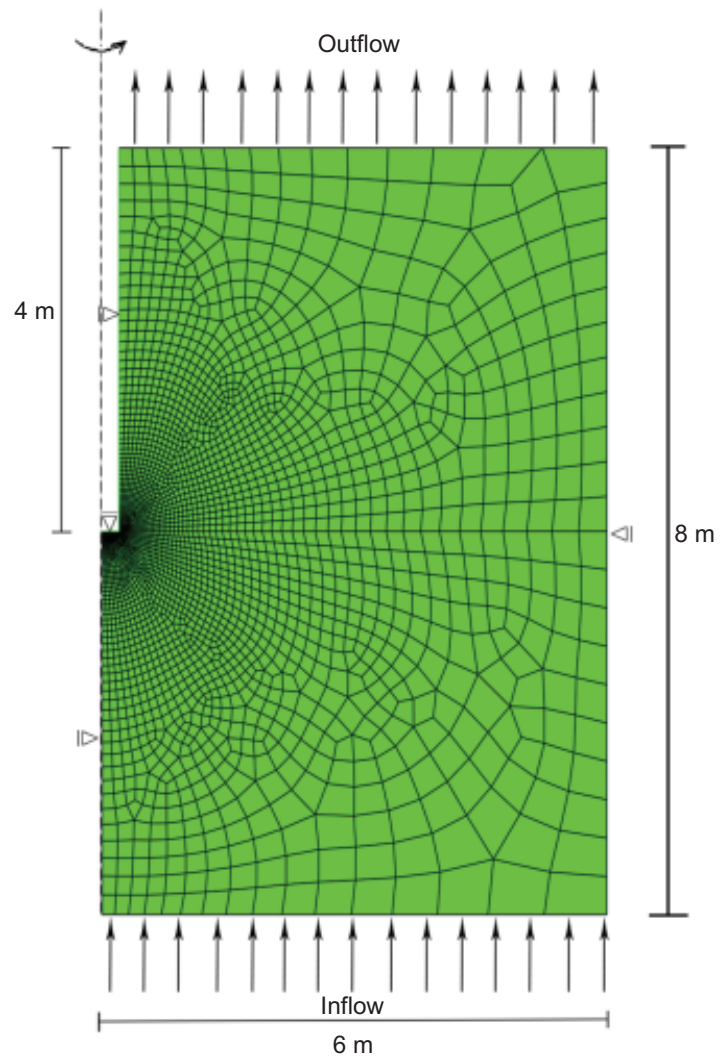

Fig. 8. Pile penetration in Chiibishi sand: axisymmetric Eulerian finite-element models and boundary conditions, in which rigid pile is fixed, inflow material velocity is $0 \cdot 01 \mathrm{~m} / \mathrm{s}$, and initial vertical and horizontal stresses are defined by nominating $\sigma_{\mathrm{v} 0}$ and $\sigma_{\mathrm{h} 0}$

by applying designated external pressures. Although such sands typically have lower unit weights, a unit weight of $\gamma=20 \mathrm{kN} / \mathrm{m}^{3}$ was employed without much effect on the results; this was confirmed by performing a separate sensitivity analysis (not shown). The diameter of the rigid pile is $D=0.2 \mathrm{~m}$; the shear stress at the interface is calculated using the Coulomb friction model with friction coefficient $\mu=\tan (\phi / 2)=0.4$ (Durgunoglu \& Mitchell, 1975).

Next, the experimental observations of the deformation patterns given by Figs 9(a), 9(c) and 9(e) will be predicted numerically using the model. This is achieved by employing a technique similar to the strain path method, which was originally proposed by Baligh (1985) in terms of inviscid fluid streamlines and then by Einav \& Randolph (2005) using the upper-bound theory of plasticity. Here, this technique is adapted to employ the velocity profiles obtained by the present numerical model, from the nodal velocities at steady state corresponding to the fixed Eulerian FEM mesh, and corresponding to steady state. The steady state is numerically determined after the penetration is sufficiently large such that the picture of breakage and plastic strains cease to evolve, with $S / D$ of more than ten. The velocity field at any point in the problem domain was calculated by employing shape functions interpolating the nodal velocities corresponding to the numerical steady state. The positions and trajectories of the material points were tracked from their original positions. This procedure provides the numerical pictures of the soil deformation after the relevant $S / D$ penetration has been attained, by tracking the steady-state streamlines. Strictly speaking, the experimental pictures do not correspond to steady state. However, the use of the steady-state velocity field from the Eulerian FEM seems to facilitate excellent approximation to the deformation patterns, as proven by the agreement between the numerical solutions (Figs 9(b), 9(d) and 9(f)) and the non-steady experimental deformation patterns (Figs 9(a), 9(c) and 9(e)).

In addition, the numerical model can be further assessed in the more traditional way, by comparing the numerical and experimental tip resistances as the piles penetrate through the soil (Fig. 10). The agreement between these curves is very good.

\section{A NEW FORMULA FOR END-BEARING CAPACITY FACTOR}

One way to express the end-bearing capacity of piles is often written as

$$
q_{\mathrm{p}}=N_{\mathrm{q}} \sigma_{\mathrm{v} 0}
$$

where $\sigma_{\mathrm{v} 0}$ represents the initial vertical stress at a depth corresponding to the pile tip, and $N_{\mathrm{q}}$ is the dimensionless end-bearing capacity factor. More recently it has become more common to express the end-bearing capacity of piles using the initial effective confining pressure, $p_{0}$, rather than $\sigma_{\mathrm{v} 0}($ Vesic, 1973a, 1975; Al-Awquati, 1975), as

$$
\begin{aligned}
& q_{\mathrm{p}}=N_{\mathrm{q}}^{*} p_{0} \\
& N_{\mathrm{q}}^{*}=\frac{3}{1+2 K_{0}} N_{\mathrm{q}}
\end{aligned}
$$

where the modified end-bearing capacity factor $N_{\mathrm{q}}^{*}$ depends on $N_{\mathrm{q}}$ through the coefficient of lateral earth pressure at rest, $K_{0}$. Both $N_{q}$ and $N_{\mathrm{q}}^{*}$ are defined as functions of the frictional angle at the critical state. Various equations have been proposed in the past for these factors, and a few of the better-known ones are listed in Appendix 2.

For crushable soils, in addition to the effects of confining pressure $p_{0}$ on the bearing capacity (Fig. 10), it is reasonably expected that the critical comminution pressure $p_{\mathrm{c}}$ will also play an essential role in the bearing capacity equation. The authors' numerical analysis (Fig. 11) shows the dependence of $N_{\mathrm{q}}^{*}$ on both the confining and critical comminution pressures, through a sort of overconsolidation ratio, $p_{0} / p_{c}$. According to this analysis $N_{\mathrm{q}}^{*}$ is expressed by a power law of $p_{0} / p_{c}$, which can be represented by a straight line in a $\log -\log$ plot such as that given in Fig. 11(b) to give the relation 


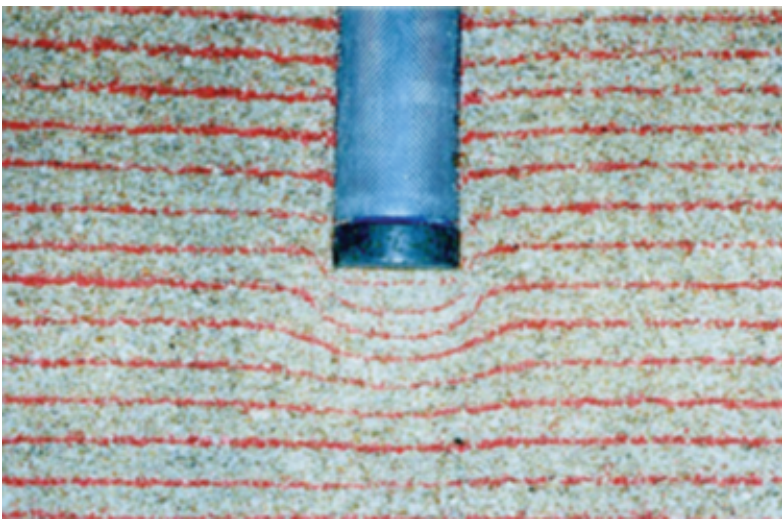

(a) $S / D=0.5$, experiment

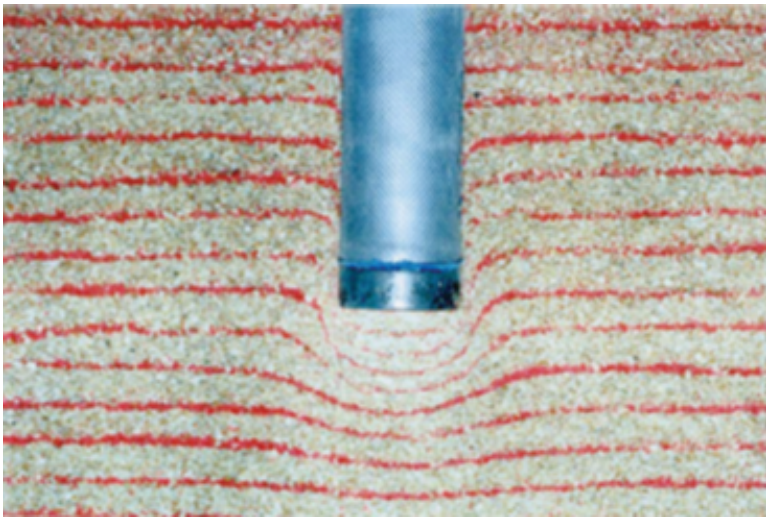

(c) $S / D=1$, experiment

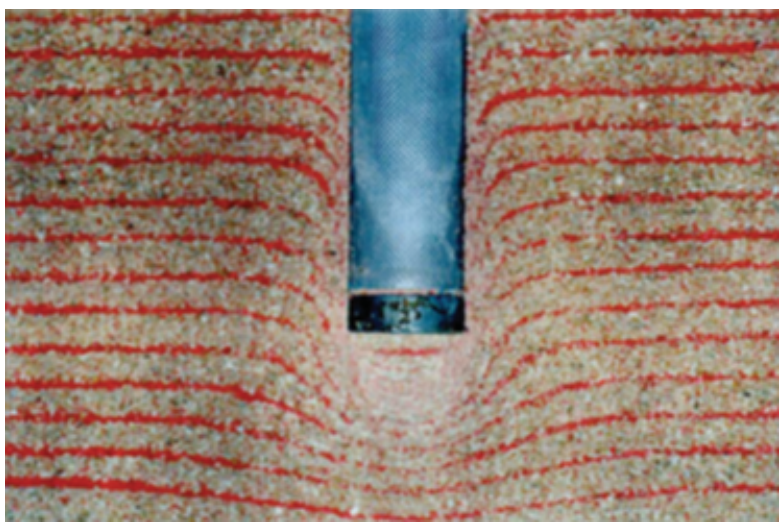

(e) $S / D=3$, experiment

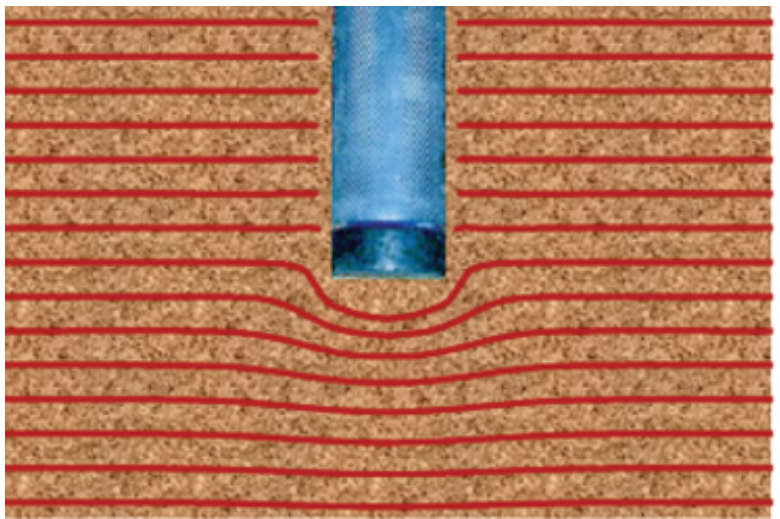

(b) $S / D=0.5$, theory

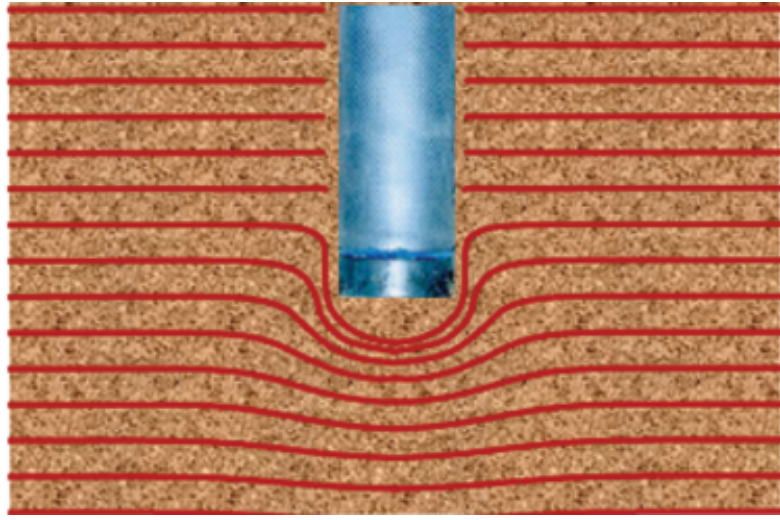

(d) $S / D=1$, theory

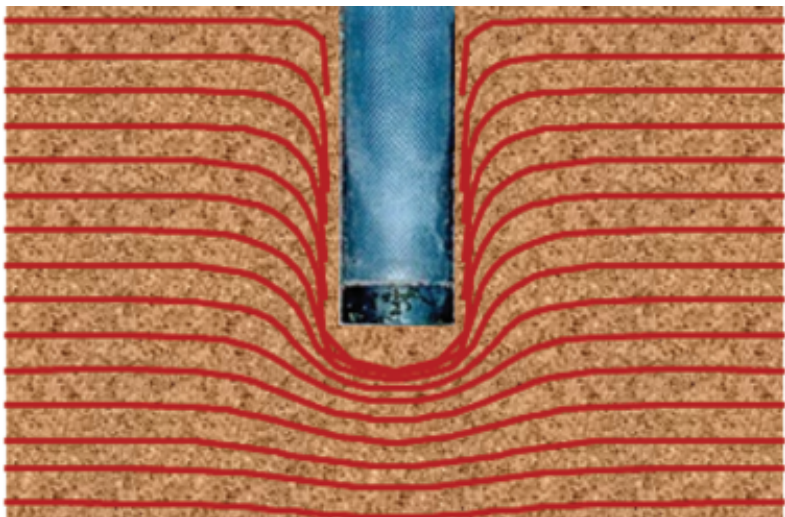

(f) $S / D=3$, theory

Fig. 9. Pile penetration in Chiibishi sand: (a), (c), (e) experimental observation (Kuwajima et al., 2009; lines are coloured sand); (b), (d), (f) corresponding numerical predictions of soil deformation ( $S$, penetration depth; $D$, pile diameter)

$$
N_{\mathrm{q}}^{*}=\alpha\left(\frac{p_{\mathrm{c}}}{p_{0}}\right)^{2 \beta}
$$

where $\alpha$ and $\beta$ are parameters that will be found later to depend on the material stiffness $(G$ and $K)$ and the friction parameter $(M)$.

Since the power law relation in equation (17) is controlled by two parameters, $\alpha$ and $\beta$, it is necessary to quantify their dependence on the fundamental model constants: the shear modulus, $G$; the bulk modulus, $K$; the friction coefficient at critical states, $M$; and the coupling angle, $\omega$. Numerical results for the variation of $\alpha$ and $\beta$ with respect to penetration depth (Table 2) shows that $\beta$ apparently increases with the penetration depth until steady state, while the change in $\alpha$ is not monotonic. A comparison has been made by converting the experimental data from Kuwajima et al. (2009) into the definition of $N_{\mathrm{q}}^{*}$. It is found that their experimental $\alpha$ ranges from 17.96 to 33.66 , and $\beta$ from 0.28 to 0.35 up to $3 D$ penetration.

The results in Table 2 indicate that $\beta$ reaches a constant value of 0.42 at steady state. This constant value can be confirmed by a parametric study employing different values of $G / K, M$ and $\omega$. The numerical results are depicted in Fig. 12 , and the corresponding values of $\alpha$ and $\beta$ are listed in Table 3. It can be seen that $\beta=0.42$ is independent of the other parameters. By contrast, $\alpha$ grows with increasing $G / K$ and $M$. Also, both $\alpha$ and $\beta$ are independent of the coupling angle $\omega$, and therefore the end-bearing capacity is also independent of $\omega$. Therefore $\alpha$ can be expressed as a function of $M$ and $G / K$ only, the relationship of which is obtained from another series of simulations using different values for $G / K$ and $M$. The results obtained, listed in Table 4, give the following relationship (with deviation errors always less than $4 \cdot 5 \%$ ) 


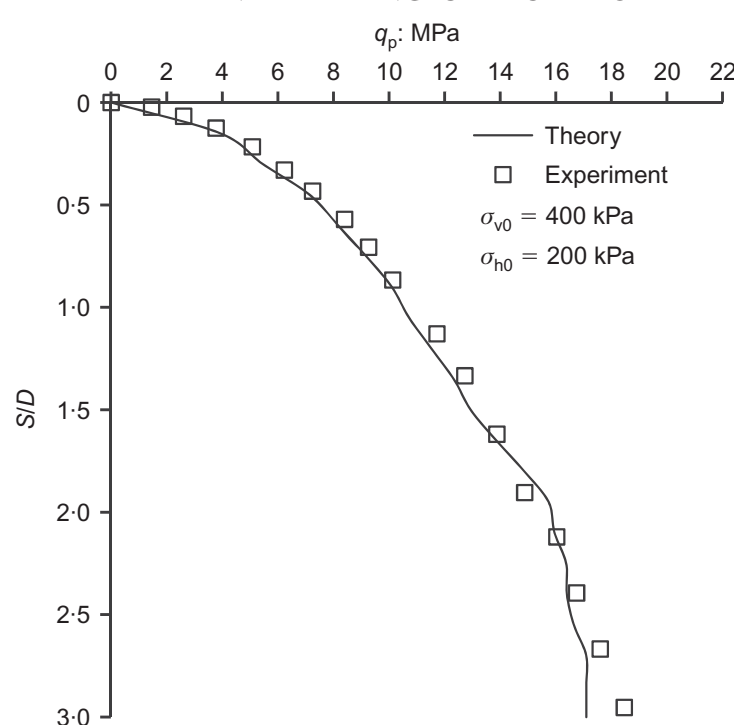

(a)

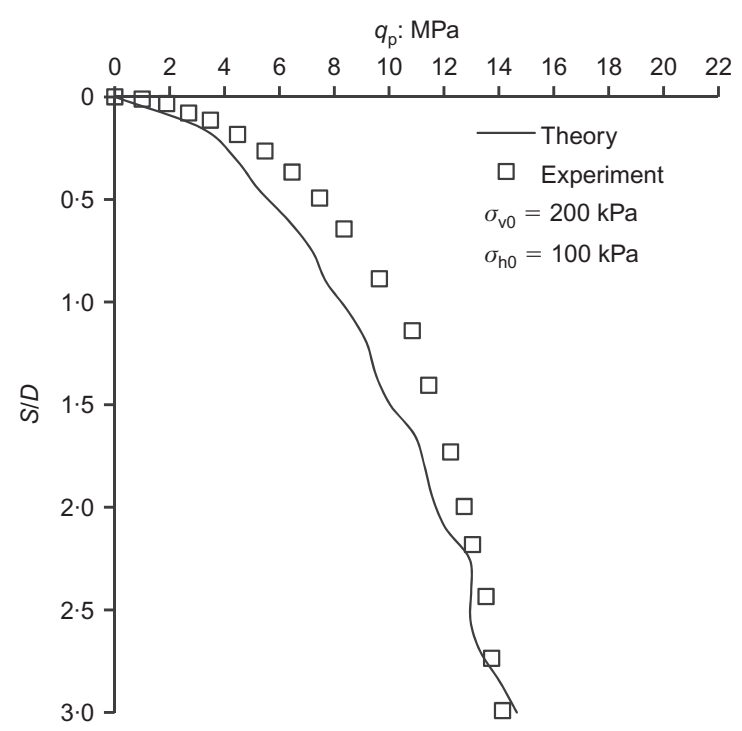

(c)

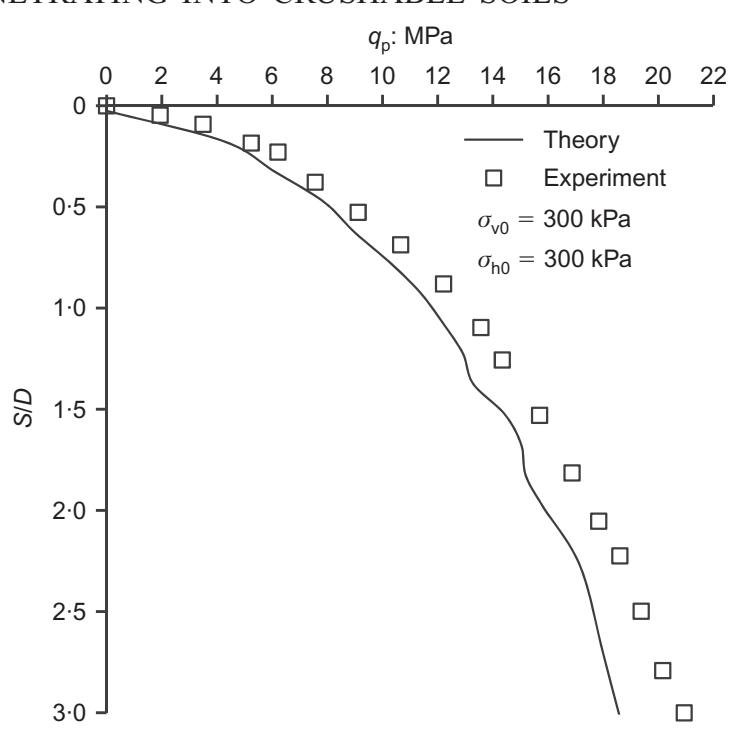

(b)

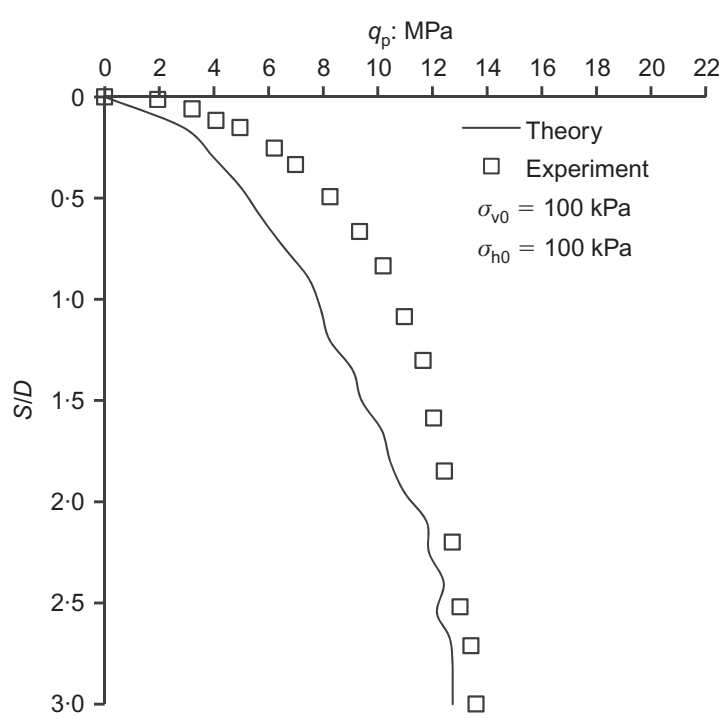

(d)

Fig. 10. Pile penetration in Chiibishi sand $\left(D_{\mathrm{r}}=90 \%\right)$ : experimental measurement (Kuwajima et al., 2009) and numerical prediction of end-bearing capacity for different initial stress conditions ( $S$, penetration depth; $D$, pile diameter)

$$
\alpha=M^{3}+14\left(\frac{G}{K}\right)
$$

Expressing $G / K$ in terms of the Poisson's ratio $v$, and using the standard approximation $M=6 \sin \phi /(3-\sin \phi)$, the complete expression for $N_{\mathrm{q}}^{*}$ can be given as

$$
N_{\mathrm{q}}^{*}=\left[\left(\frac{6 \sin \phi}{3-\sin \phi}\right)^{3}+7\left(\frac{3-6 v}{1+v}\right)\right]\left(\frac{p_{\mathrm{c}}}{p_{0}}\right)^{0 \cdot 84}
$$

Next, note that, according to the breakage model, the critical comminution pressure $p_{\mathrm{c}}$, which marks the onset of isotropic yielding, depends on the GSD by way of $\vartheta$ (see equation (11)) according to

$$
N_{\mathrm{q}}^{*}=\left[\left(\frac{6 \sin \phi}{3-\sin \phi}\right)^{3}+7\left(\frac{3-6 v}{1+v}\right)\right]\left(\frac{2 K E_{\mathrm{c}}}{\vartheta p_{0}^{2}}\right)^{0 \cdot 42}
$$

Therefore the last equation for the end-bearing capacity of piles penetrating into sand is here dependent on the confining pressure $p_{0}$, the GSD (via $\vartheta$ ), the critical breakage energy $E_{\mathrm{c}}$, the elastic Young's modulus $E$ and Poisson's ratio $v)$, and the friction angle $\phi$. The performance of this new formula is compared in Fig. 13 for the two typical crushable soils with four previous ones by Prandtl (1921), Terzaghi (1943) and Vesic (1973b, 1975). Both the Prandtl and Terzaghi solutions are pressure independent, unlike the experimental results, which display high pressure sensitivity. It appears that, of the earlier formulae, the two equations by Vesic are the most successful in reproducing the pressure sensitivity, but either overestimate or underestimate the true result. On the other hand, the new formula appears highly successful, both qualitatively and quantitatively. Note that, unlike the previous formulae, the new one depends on the critical comminution pressure $p_{\mathrm{c}}$ (a value that was therefore employed identically to make the pressure non-dimensional in all the solutions). This critical comminution pressure depends on the GSD, which for the first time truly underpins the compressibility of crushable soils.

The influence of the initial GSDs on $N_{\mathrm{q}}^{*}$ is further explored in Fig. 14, based on the parameters for Dog's Bay sand (see Table 1), where the initial GSD is a power law, as indicated in the insert plot in this figure. The initial GSD is represented by the power law coefficient $\beta$ (instead of $\alpha$ in equation (13)). It is evident that the end-bearing capacity increases as the level of grain-size polydispersity increases. 


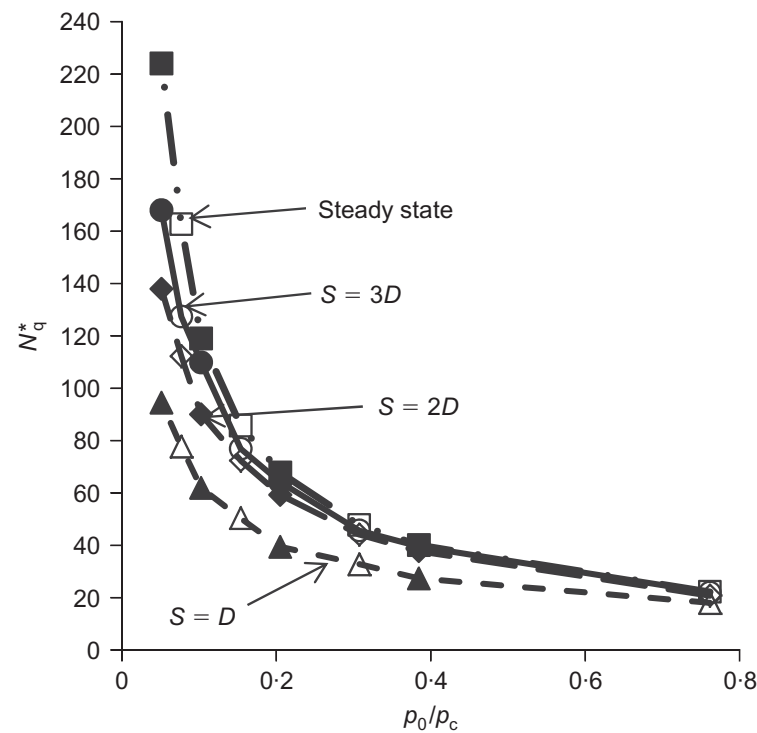

(a)

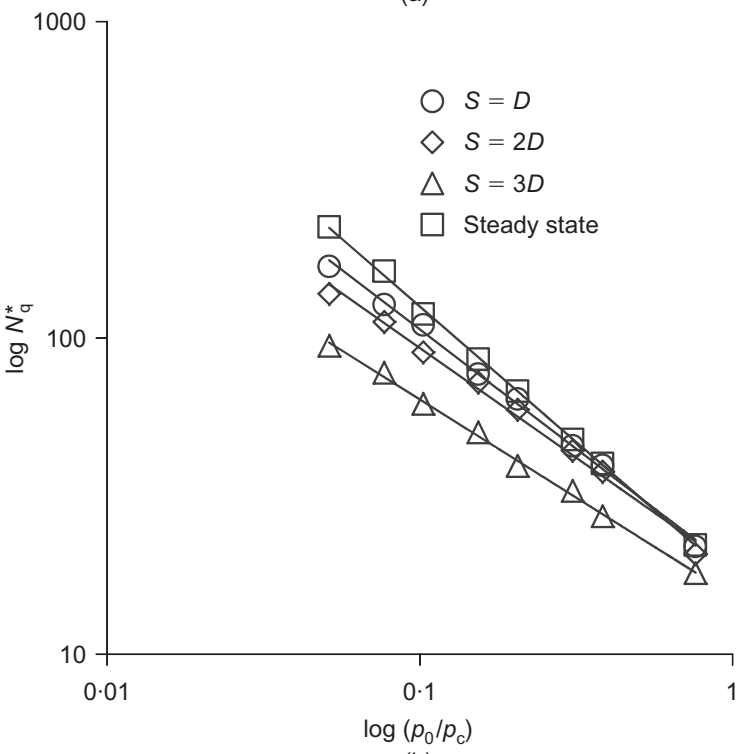

(b)

Fig. 11. Modified end-bearing capacity factor $N_{\mathrm{q}}^{*}$ against: (a) $p_{0} / p_{\mathrm{c}}$ (solid symbols, $K_{0}=0.5$; open symbols, $\left.K_{0}=1 \cdot 0\right)$; (b) $\log \left(p_{0} / p_{\mathrm{c}}\right)$ (solid lines represent fitting curves; $S$, penetration depth; $D$, pile diameter; model parameters listed in Table 1)

Table 2. Effects of penetration depth on $\alpha$ and $\beta$

\begin{tabular}{l|c|c|c}
\hline Penetration & $\alpha$ & $\beta$ & $R^{2}$ \\
\hline$S=D$ & $15 \cdot 06$ & $0 \cdot 31$ & 0.9975 \\
$S=2 D$ & $18 \cdot 25$ & 0.35 & 0.9922 \\
$S=3 D$ & $18 \cdot 10$ & 0.38 & 0.9960 \\
Steady & 17.41 & 0.42 & 0.9995 \\
\hline
\end{tabular}

Finally, the effect of initial porosity, $n_{0}$, could be taken into account indirectly by considering the approximation in equation (12). Accordingly, the end-bearing capacity factor is found to depend on the initial porosity through $N_{\mathrm{q}}^{*} \propto\left(1-n_{0}\right)^{0.84}$. This means that denser sands should have higher end-bearing capacity, in agreement with experimental findings by Konrad (1998) and Klotz \& Coop (2001). A more consistent derivation could follow by carrying out a new set of FEM simulations with the more advanced constitutive breakage-porosity model of Rubin \& Einav (2011).

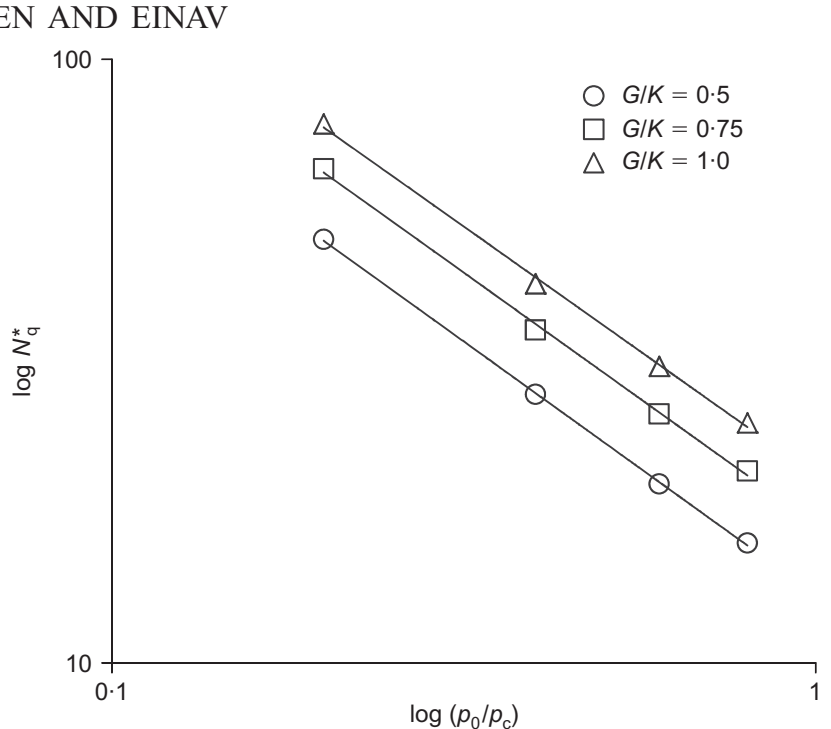

(a)

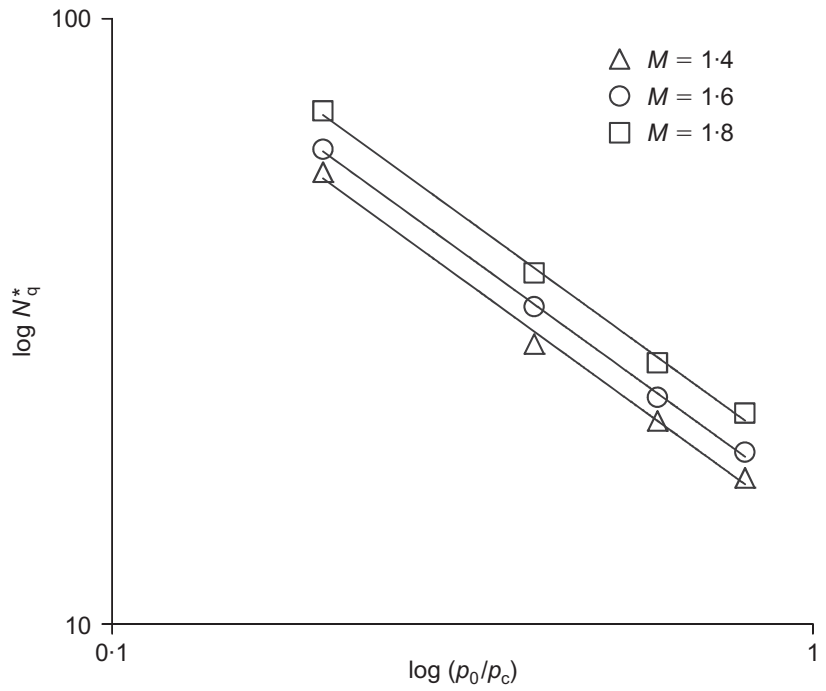

(b)

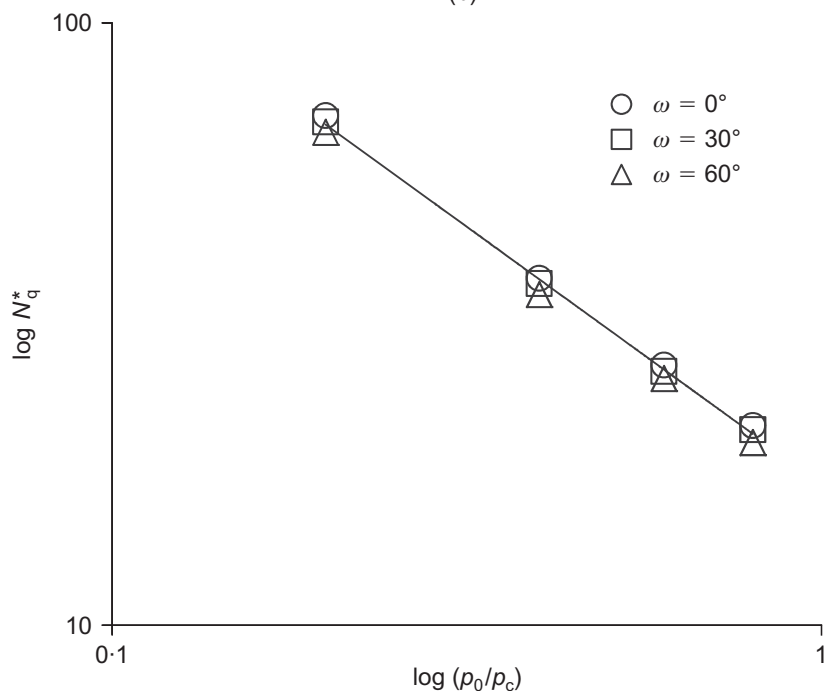

(c)

Fig. 12. Modified end-bearing capacity factor $N_{\mathrm{q}}^{*}$ against $\log \left(p_{0} / p_{\mathrm{c}}\right)$ at steady-state penetration, $K_{0}=1$ : (a) effects of $G / K$; (b) effects of $M$; (c) effects of $\omega$ (other model parameters, if not varied, are listed in Table 1)

\section{CONCLUSION}

The end-bearing capacity of piles penetrating into crushable soils is analysed within the context of breakage mechanics theory. The paper has highlighted the importance of 
Table 3. Effects of $G / K, M$, and $\omega$ on $\alpha$ and $\beta$ for steady-state penetration

\begin{tabular}{l|c|c|c|c}
\hline Parameter & Value & $\alpha$ & $\beta$ & $R^{2}$ \\
\hline$G / K$ & 0.5 & 12.98 & 0.42 & 0.999 \\
& 0.75 & 16.98 & 0.42 & 0.998 \\
$M$ & 1.0 & 20.55 & 0.42 & 0.998 \\
& 1.4 & 14.12 & 0.42 & 0.996 \\
$\omega:$ degrees & 1.6 & 15.68 & 0.42 & 0.999 \\
& 1.8 & 17.99 & 0.42 & 0.998 \\
& 0 & $17 \cdot 18$ & 0.42 & 0.999 \\
& 60 & & & \\
\hline
\end{tabular}

Table 4. Effects of $G / K$ and $M$ on $\alpha$ (for $\beta=0 \cdot 42)$

\begin{tabular}{l|c|c|c}
\hline & $M=1.4$ & $M=1 \cdot 6$ & $M=1 \cdot 8$ \\
\hline$G / K=0.5$ & $10 \cdot 10$ & 10.97 & 12.65 \\
$G / K=0.75$ & 13.47 & 14.57 & 16.24 \\
$G / K=1.0$ & 16.03 & 17.45 & 20.04 \\
\hline
\end{tabular}

resorting to fundamental failure mechanisms for crushable soils in determining the end-bearing capacity. Breakage mechanics theory does not only improve understanding of the constitutive response of crushable soils, but also provides an insight into problems such as the bearing capacity, and consequently results in predictions that are free from empirical parameters. This is particularly important for practical purposes, given the reliability issues in interpreting and incorporating data from both laboratory and field tests in the prediction of bearing capacity. The proposed end-bearing capacity equation captures the effects of material crushability, in terms of the initial GSD, the confining pressure, the

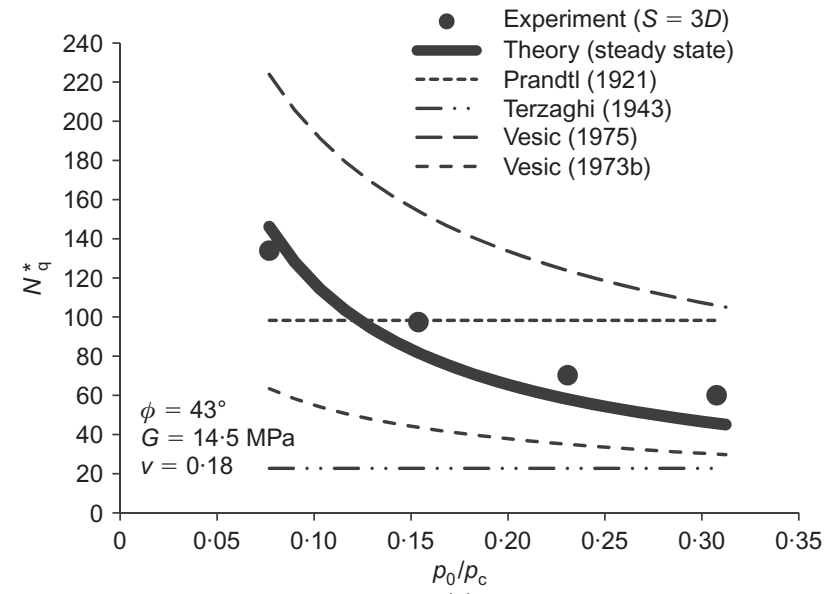

(a)

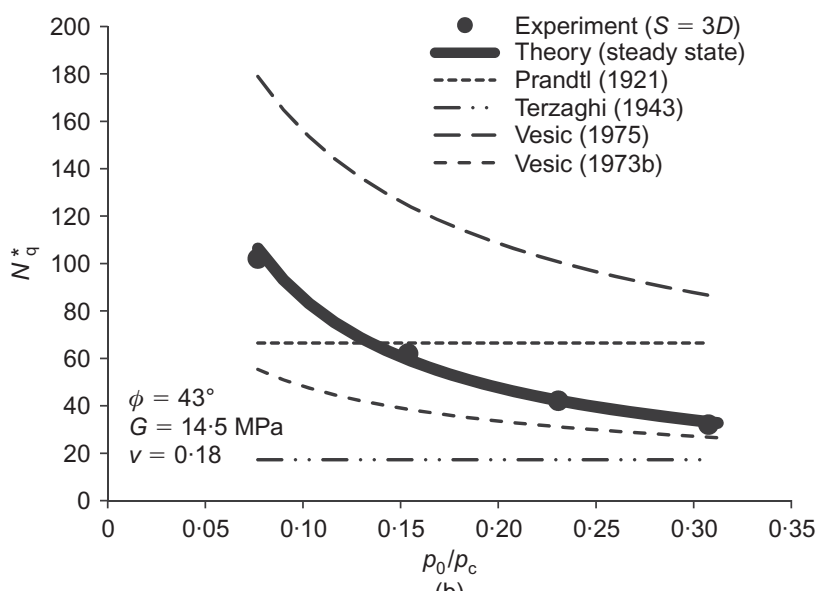

(b)

Fig. 13. Modified end-bearing capacity factor $N_{\mathrm{q}}^{*}$ against $p_{0} / p_{\mathrm{c}}$ for: (a) Chiibishi sand; (b) Dog's Bay sand (experimental data from Kuwajima et al., 2009)

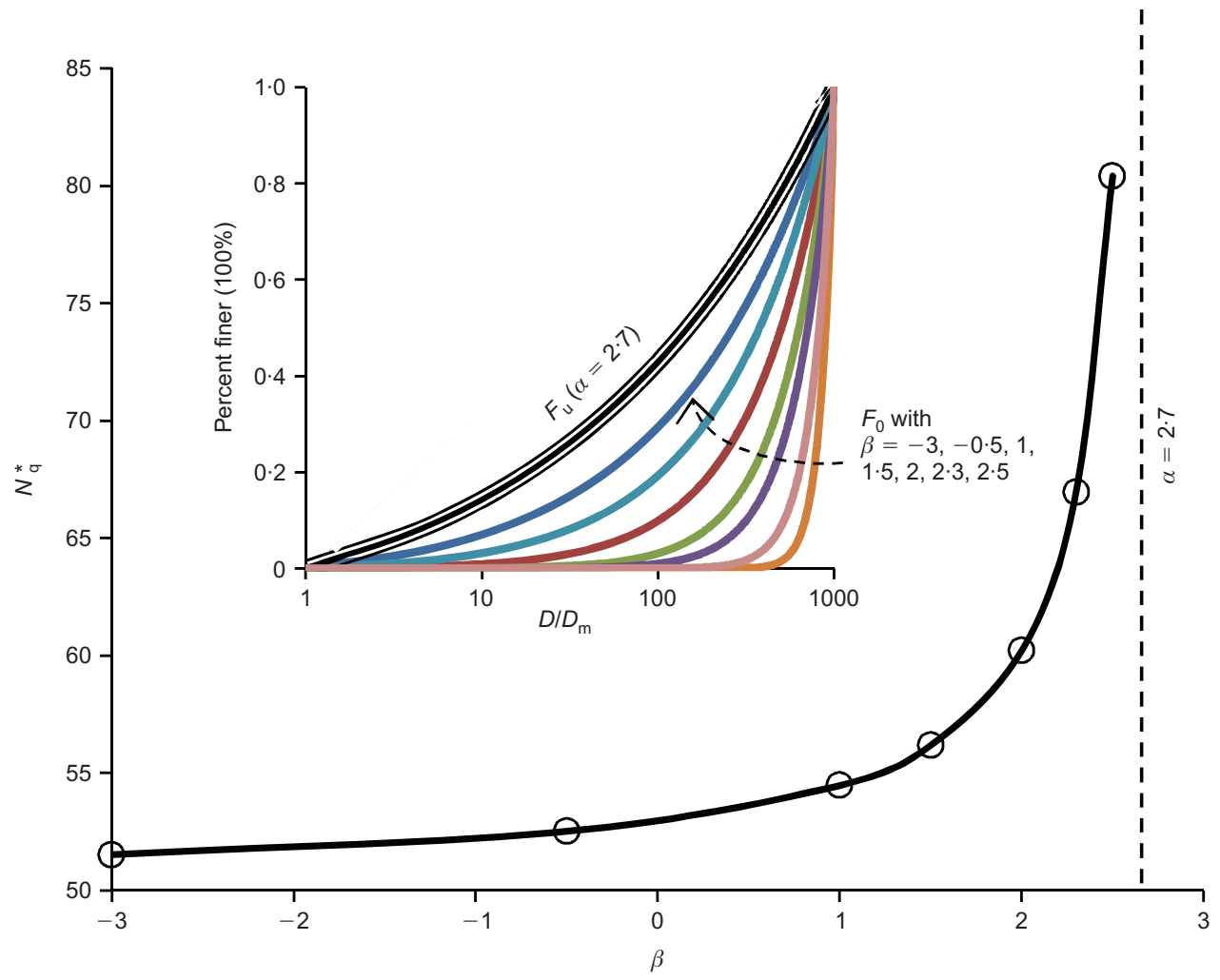

Fig. 14. Influence of initial grain size distributions (GSDs) on $N_{\mathrm{q}}^{*}$ for Dog's Bay sand described by the shape parameter $\beta$. Inset shows the corresponding GSDs, always with an ultimate GSD defined by $\alpha=2 \cdot 7$, and a minimum grain size always being $D_{\mathrm{m}}$ 
critical breakage energy, and the constants of elasticity. The result appears to provide a more reliable prediction of capacities compared with any of the previous equations. The new bearing capacity equation can benefit the future design of pile foundations in sand materials, and can be used as a reference for engineering purposes.

\section{ACKNOWLEDGEMENTS}

This research was supported by the Australian Research Council through the ARC Discovery Projects funding scheme (project number DP0986876). The second author wishes to thank the University of Sydney for support through the postdoctoral fellowship scheme.

\section{APPENDIX 1: FINITE-ELEMENT IMPLEMENTATION}

The implementation of the breakage constitutive model described in the paper is briefly presented for numerical analyses using the finite-element method (FEM). The tensorial form of the triaxial model is used. The triaxial stresses and strains are written in terms of the stress and strain invariants as

$$
p=-\frac{1}{3} \sigma_{k k} ; q=\sqrt{\frac{3}{2} s_{i j} s_{i j}} ; \varepsilon_{\mathrm{v}}=-\varepsilon_{k k} ; \varepsilon_{\mathrm{s}}=\sqrt{\frac{2}{3} e_{i j} e_{i j}}
$$

where $\delta_{i j}$ is the Kronecker delta

$$
s_{i j}=\sigma_{i j}-\frac{\sigma_{k k}}{3} \delta_{i j} \text { and } e_{i j}=\varepsilon_{i j}-\frac{\varepsilon_{k k}}{3} \delta_{i j}
$$

The elastic component of the constitutive equations (equations (3) and (4)) of the model can be rewritten in tensorial form as

$$
\sigma_{i j}=(1-\vartheta B) D_{i j k l} \varepsilon_{k l}^{\mathrm{e}}
$$

with the yield function given as

$$
y=\frac{\vartheta}{2 E_{\mathrm{c}}}\left(\frac{p^{2}}{K}+\frac{q^{2}}{3 G}\right)\left(\frac{1-B}{1-\vartheta B}\right)^{2}+\left(\frac{q}{M p}\right)^{2}-1 \leqslant 0
$$

and flow rules

$$
\begin{aligned}
& \delta \varepsilon_{i j}^{\mathrm{p}}=\delta \lambda\left[-\frac{2(1-B)^{2} E_{\mathrm{B}} \sin ^{2} \omega}{p E_{\mathrm{c}}} \frac{\delta_{i j}}{3}+\frac{3 s_{i j}}{M^{2} p^{2}}\right]=\delta \lambda Q_{i j} \\
& \delta B=\delta \lambda \frac{2(1-B)^{2} \cos ^{2} \omega}{E_{\mathrm{c}}}=\delta \lambda R
\end{aligned}
$$

The aim is to calculate the stress increment $\delta \sigma_{i j}$, given the current state of the material point at X (Fig. 15) and the strain increment $\delta \varepsilon_{i j}$ obtained from the non-linear finite-element analysis. The case where yielding occurs is considered, indicated by $y^{\text {trial }}>0$ at trial point $Y$. This trial stress point is obtained by assuming linear elastic behaviour with secant stiffness $(1-\vartheta B) D_{i j k l}$ for the strain increment $\delta \varepsilon_{i j}$, resulting in the trial stress increment $\delta \sigma_{i j}^{\text {trial }}=(1-\vartheta B) D_{i j k l} \delta \varepsilon_{k l}$. Performing a Taylor expansion of the yield function (equation (24)) at the trial point Y (Fig. 15), the following is obtained

$$
y=y^{\text {trial }}+\frac{\partial y}{\partial B} \delta B+\left(\frac{\partial y}{\partial p} \frac{\partial p}{\partial \sigma_{i j}}+\frac{\partial y}{\partial q} \frac{\partial q}{\partial \sigma_{i j}}\right) \delta \sigma_{i j}
$$

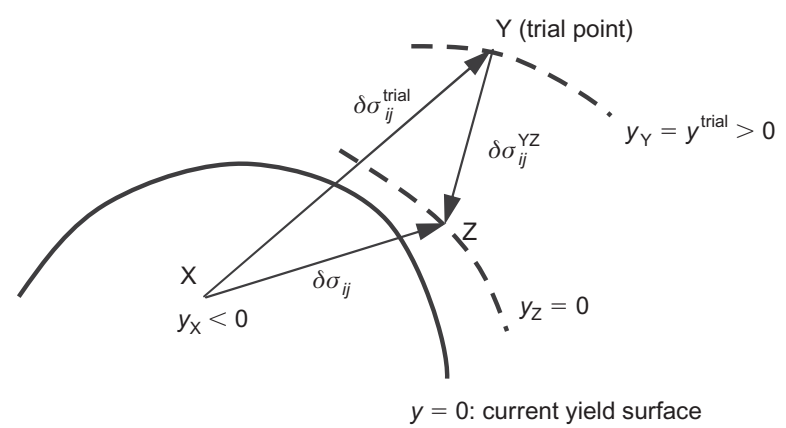

Fig. 15. Schematic diagram of the stress return algorithm
Substituting the flow rules (equations (25) and (26)) and the stress increment in the form

$$
\delta \sigma_{i j}=-(1-\vartheta B) D_{i j k l} \delta \varepsilon_{k l}^{\mathrm{p}}-\frac{\vartheta \sigma_{i j}}{1-\vartheta B} \delta B
$$

into equation (27) results in (noting that the total strain increment has been used to obtain the trial point $\mathrm{Y}$, and hence there is no total strain increment beyond this trial point)

$$
\begin{aligned}
y= & y^{\text {trial }}+\left\{\frac{\partial y}{\partial B} R-\left(\frac{\partial y}{\partial p} \frac{\partial p}{\partial \sigma_{i j}}+\frac{\partial y}{\partial q} \frac{\partial q}{\partial \sigma_{i j}}\right)\right. \\
& \left.\times\left[(1-\vartheta B) D_{i j k l} Q_{k l}+\frac{\vartheta \sigma_{i j}}{1-\vartheta B} R\right]\right\} \delta \lambda
\end{aligned}
$$

where $Q_{k l}$ and $R$ are defined in equations (25) and (26). It is implicitly implied here that all variables and quantities in equation (29) are evaluated at trial point Y. Enforcing the yield condition at point Z, $y=y_{Z}=0$, the multiplier $\delta \lambda$ can be obtained in the form

$$
\begin{aligned}
\delta \lambda= & \frac{-y^{\text {trial }}}{\left\{\frac{\partial y}{\partial B} R-\left(\frac{\partial y}{\partial p} \frac{\partial p}{\partial \sigma_{i j}}+\frac{\partial y}{\partial q} \frac{\partial q}{\partial \sigma_{i j}}\right)\right.} \\
& \left.\times\left[(1-\vartheta B) D_{i j k l} Q_{k l}+\frac{\vartheta \sigma_{i j}}{1-\vartheta B} R\right]\right\}
\end{aligned}
$$

The stress increment $\delta \sigma_{i j}^{\mathrm{YZ}}$ then follows as

$$
\delta \sigma_{i j}^{\mathrm{YZ}}=-\left[(1-\vartheta B) D_{i j k l} Q_{k l}+\frac{\vartheta \sigma_{i j}}{1-\vartheta B} R\right] \delta \lambda
$$

The total stress increment $\delta \sigma_{i j}$ is obtained as the sum of $\delta \sigma_{i j}^{\text {trial }}$ and $\delta \sigma_{i j}^{\mathrm{YZ}}$ (Fig. 15),

$$
\delta \sigma_{i j}=\delta \sigma_{i j}^{\text {trial }}+\delta \sigma_{i j}^{\mathrm{YZ}}
$$

The above algorithm has been implemented in the commercial finiteelement package Abaqus (2007) in the form of a VUMAT subroutine.

\section{APPENDIX 2: PREVIOUS END-BEARING CAPACITY FACTORS}

Prandtl (1921) proposed an end-bearing capacity factor for flat strip surfaces punching through idealised weightless incompressible media with assumed general shear failure

$$
N_{\mathrm{q}}=\tan ^{2}\left(\frac{\pi}{4}+\frac{\phi}{2}\right) \mathrm{e}^{\pi \tan \phi}
$$

The assumption of general shear failure, however, is known to be problematic for compressible soils. In such cases, the shear failure tends to be more local.

Terzaghi (1943) suggested modifying the equation above by incorporating the reduced friction angle $\phi_{\mathrm{r}}=\tan ^{-1}\left(\frac{2}{3} \tan \phi\right)$ to account for the local shear in compressible soils

$$
N_{\mathrm{q}}=\tan ^{2}\left(\frac{\pi}{4}+\frac{\phi_{\mathrm{r}}}{2}\right) \mathrm{e}^{\pi \tan \phi_{\mathrm{r}}}
$$

Both equation (33) and equation (34) could be corrected in the usual way to allow these factors to be applied to the circular flat surface shape of typical piles. However, these equations still do not account for the increase of soil strength with depth. Moreover, equation (34) is known to give overly conservative answers for piles (Vesic, 1973b).

Vesic (1973b) first attempted to modify Prandtl's equation (33), by considering the soil compressibility. For that reason Vesic introduced the reduction compressibility factor $\xi_{\mathrm{qc}}$ (here specified for the case of a flat circular surface)

$$
\begin{aligned}
& N_{\mathrm{qc}}=N_{\mathrm{q}} \xi_{\mathrm{qc}} \\
& \xi_{\mathrm{qc}}=\exp \left[(3.07 \sin \phi) \frac{\log \left(2 I_{\mathrm{r}}\right)}{1+\sin \phi}-3.8 \tan \phi\right]
\end{aligned}
$$

where for sand the rigidity index $I_{\mathrm{r}}=G /\left(\sigma_{\mathrm{v} 0} \tan \phi\right)$ was introduced to capture the influence of the initial (effective) vertical stress $\sigma_{\mathrm{v} 0}$.

Vesic (1975) proposed another equation, an alternative to his own equations (35) and (36), specified in terms of $N_{\mathrm{q}}^{*}$ as 


$$
\begin{aligned}
& N_{\mathrm{q}}^{*}=N_{\mathrm{qc}} \xi_{\mathrm{qc}} \\
& N_{\mathrm{qc}}=\tan ^{2}\left(\frac{\pi}{4}+\frac{\phi}{2}\right) \mathrm{e}^{\left(\frac{\pi}{2}-\phi\right) \tan \phi} \\
& \xi_{\mathrm{qc}}=\frac{3}{3-\sin \phi}\left(I_{\mathrm{rr}}\right)^{\frac{4 \sin \phi}{3(1+\sin \phi)}}
\end{aligned}
$$

The main conceptual change may be seen through the modified rigidity index $I_{\mathrm{rr}}=I_{\mathrm{r}} /\left(1+\bar{\varepsilon}_{\mathrm{v}} I_{\mathrm{r}}\right)$, which adds irreversible compressibility effects by way of $\bar{\varepsilon}_{\mathrm{v}}$, the average volumetric strain in the plastic zone. Unfortunately, volumetric strain is a referencedependent measure that requires a lot of guesswork. More critically, it was recommended to take $\bar{\varepsilon}_{\mathrm{v}}=0$ for soils that are initially at their densest state (e.g. corresponding to the experiments evaluated in the current paper). Unfortunately, the notion of densest state in crushable soils is ambiguous. This is because, in such soils, the maximum and minimum densities depend on the GSD, which by itself varies during the deformation.

The above four formulae are plotted in Fig. 13 against equation (20) for both the Chiibishi and Dog's Bay sands. Note that the experimental conditions provide $K_{0}=1$, and therefore $N_{\mathrm{q}}$ is the same as $N_{\mathrm{q}}^{*}$. Since Vesic's formulae (equations (35)-(39)) include $\sigma_{\mathrm{v} 0}$ through the use of $I_{\mathrm{r}}$, the corresponding curves are indeed pressuredependent. In the authors' equation, both the compressibility of the soil and the initial GSD are shown through the critical comminution pressure, $p_{\mathrm{c}}$. The initial GSD in the current experiments was fixed. It is recommended that future experiments explore the effect of the initial GSD on the end-bearing capacity, in a way that could be evaluated using the current formula (equation (20))

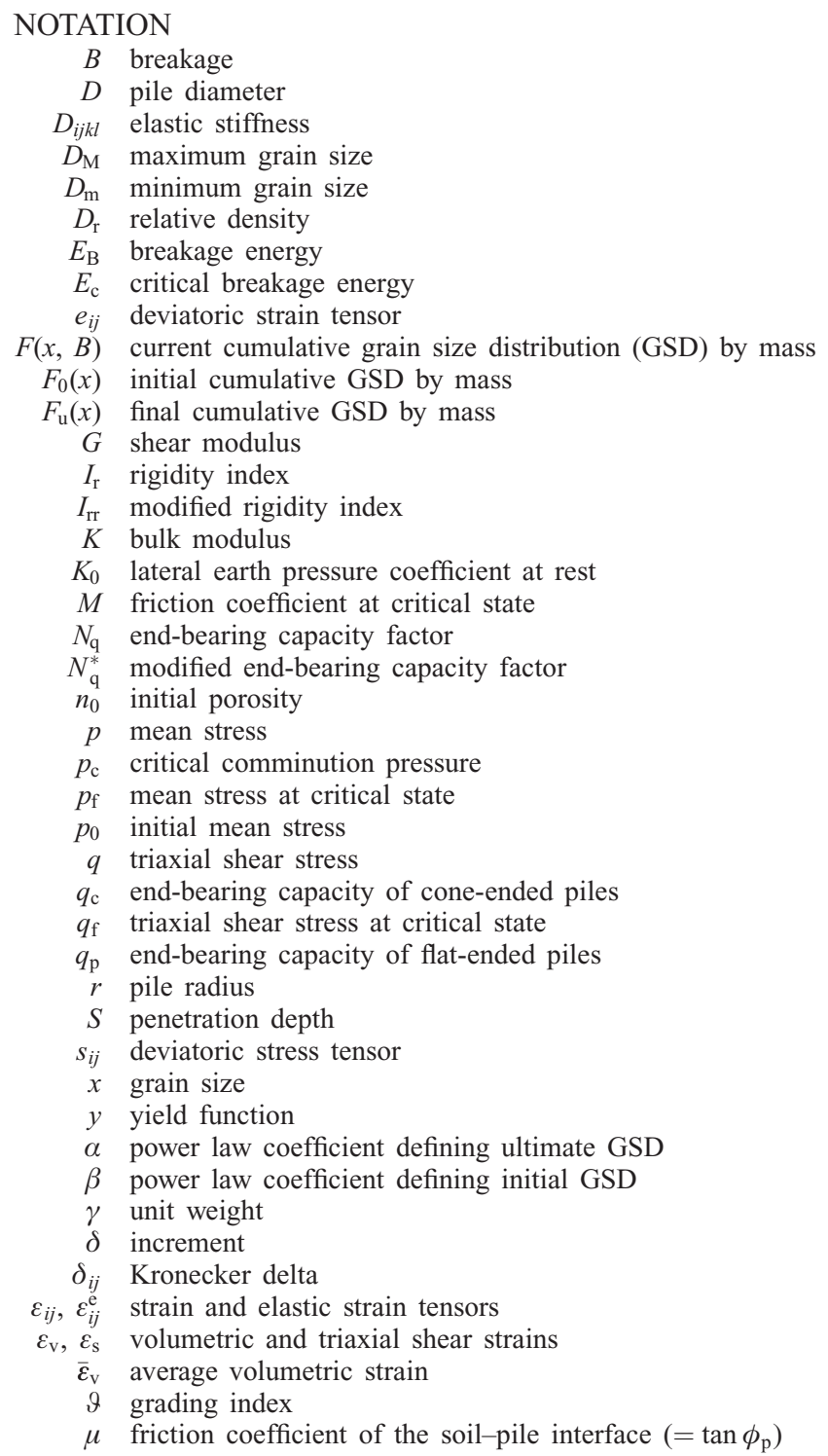

\author{
$v$ Poisson's ratio \\ $\sigma_{\mathrm{h} 0} \quad$ initial horizontal stress \\ $\sigma_{i j} \quad$ stress tensor \\ $\sigma_{\mathrm{v} 0} \quad$ initial vertical stress \\ $\phi$ friction angle of soil \\ $\phi_{\mathrm{p}}$ friction angle of soil-pile interface \\ $\Psi$ specific elastic strain energy \\ $\omega$ coupling angle
}

\section{REFERENCES}

Abaqus (2007). ABAQUS/Explicit user's manual, Version 6.7. Providence, RI, USA: Hibbitt, Karlsson \& Sorensen.

Alba, J. L. \& Audibert, J. M. E. (1999). Pile design in calcareous and carbonaceous granular materials. Proc. 2nd Int. Conf. Engng for Calcareous Sediments, Bahrain, 29-43.

Al-Awquati, A. (1975). On problems of soil bearing capacity at depth. PhD dissertation, Duke University, Durham, NC, USA

Altuhafi, F. N. \& Coop, M. R. (2011). Changes to particle characteristics associated with the compression of sands. Géotechnique 61, No. 6, 459-471, http://dx.doi.org/10.1680/geot.9.P.114.

Baligh, M. M. (1985). Strain path method. J. Soil Mech. Found. Div. ASCE 111, No. 9, 1108-1136.

Ben-Nun, O. (2010). Confined comminution of granular materials: self-organisation, attractors and patterns. $\mathrm{PhD}$ thesis, University of Sydney, Australia.

Ben-Nun, O. \& Einav, I. (2010). The role of self-organization during confined comminution of granular materials. Phil Trans. R. Soc. London A 368, No. 1910, 231-247.

Coop, M. R., Sorensen, K. K., Freitas, T. B. \& Georgoutsos, G. (2004). Particle breakage during shearing of a carbonate sand. Géotechnique 54, No. 3, 157-163, http://dx.doi.org/10.1680/ geot.2004.54.3.157.

Daouadji, A. \& Hicher, P.-Y. (2009). An enhanced constitutive model for crushable granular materials. Int. J. Numer. Analyt. Methods Geomech. 34, No. 6, 555-580.

Daouadji, A., Hicher, P.-Y. \& Rahma, A. (2001). An elastoplastic model for granular materials taking into account grain breakage. Eur. J. Mech. A Solids 20, No. 1, 113-137.

Das, A., Nguyen, G. D. \& Einav, I. (2011). Compaction bands due to grain crushing in porous rocks: a theoretical approach based on breakage mechanics. J. Geophys. Res. Solid Earth 116, http://dx.doi.org/10.1029/2011JB008265.

Datta, M., Gulhati, S. K. \& Rao, G. V. (1979). Crushing of calcareous sands during shear. Proc. 11th Ann. Offshore Technol. Conf., Houston, TX, 1459-1467.

Datta, M., Gulhati, S. K. \& Rao, G. V. (1980). An appraisal of the existing practice of determining the axial capacity of deep penetration piles in calcareous soils. Proc. 12th Ann. Offshore Technol. Conf., Houston, TX 4, 119-130.

De Gennaro, V. \& Frank, R. (2002). Insight into the simulation of calibration chamber tests. Proc. 5th Eur. Conf. Numer. Methods Geotech. Engng, Paris, 169-177.

Durgunoglu, H. T. \& Mitchell, J. K. (1975). Static penetration resistance of soils. I: Analysis. Proceedings of the conference on in situ measurement of soil properties, New York, pp. 151-171.

Einav, I. (2007a). Breakage mechanics. Part I: Theory. J. Mech. Phys. Solids 55, No. 6, 1274-1297.

Einav, I. (2007b). Breakage mechanics. Part II: Modelling granular materials. J. Mech. Phys. Solids 55, No. 6, 1298-1320.

Einav, I. $(2007 \mathrm{c})$. Fracture propagation in brittle granular matter. Proc. R. Soc. A 463, No. 2087, 3021-3035.

Einav, I. (2007d). Soil mechanics: breaking ground. Phil. Trans. R. Soc. London A, 365, No. 1861, 2985-3002.

Einav, I. \& Randolph, M. F. (2005). Combining upper bound and strain path methods for evaluating penetration resistance. Int. J. Numer. Methods Engng 63, No. 14, 1991-2016.

Foray, P., Nauroy, J.-F. \& Colliat, J.-L. (1999). Mechanisms governing the behaviour of foundations in carbonate sands and design parameters from in situ tests. Proc. 2nd Int. Conf. Engng for Calcareous Sediments, Bahrain, 55-68.

Golightly, C. R. \& Hyde, A. F. L. (1988). Some fundamental properties of carbonate sands. Proceedings of the international conference on calcareous sediments, Perth, Australia, Vol. 1, pp. 69-78. 
Hardin, B. O. (1985). Crushing of soil particles. J. Geotech. Engng 111, No. 10, 1177-1192.

Hardin, B. O. \& Black, W. L. (1966). Sand stiffness under various triaxial stresses. J. Soil Mech. Found. Engng ASCE 92, No. 2, $27-42$.

Joer, H. A., Jewell, R. J. \& Randolph, M. F. (1999). Cone penetrometer testing in calcareous sediments. Proc. 2nd Int. Conf. on Calcareous Sediments, Bahrain, 243-252.

Klotz, E. U. \& Coop, M. R. (2001). An investigation of the effect of soil state on the capacity of driven piles in sands. Géotechnique 51, No. 9, 733-751, http://dx.doi.org/10.1680/geot.2001. 51.9.733.

Konrad, J.-M. (1998). Sand state from cone penetrometer tests: a framework considering grain crushing stress. Géotechnique 48, No. 2, 201-215, http://dx.doi.org/10.1680/geot.1998.48.2.201.

Kuwajima, K., Hyodo, M. \& Hyde, A. F. L. (2009). Pile bearing capacity factors and soil crushability. J. Geotech. Geoenviron. Engng 135, No. 7, 901-913.

Lade, P. V., Yamamuro, J. A. \& Bopp, P. A. (1996). Significance of particle crushing in granular materials. J. Geotech. Engng 122, No. 4, 309-316.

McDowell, G. R. \& Bolton, M. D. (2000). Effect of particle size distribution on pile tip resistance in calcareous sand in the geotechnical centrifuge. Granular Matter 2, No. 4, 179-187.

McDowell, G. R., Bolton, M. D. \& Robertson, D. (1996). The fractal crushing of granular materials. J. Mech. Phys. Solids 44, No. 12, 2079-2101.

Muir Wood, D. \& Maeda, K. (2007). Changing grading of soil: effect on critical states. Acta Geotech. 3, No. 1, 3-14.

Nguyen, G. D. \& Einav, I. (2009). The energetics of cataclasis based on breakage mechanics. Pure Appl. Geophys. 166, No. $10-11,1693-1724$.

Poulos, H. G. (1989). The mechanics of calcareous sediments. John Jaeger Memorial Lecture. Aust. Geomech., Special edn, $8-41$.

Poulos, H. G. \& Chua, E. W. (1985). Bearing capacity of foundations on calcareous sand. Proc. 11th Int. Conf. Soil Mech. Found. Engng, San Francisco, CA 3, 1619-1622.

Prandtl, L. (1921). Uber die eindrigungsfestigkeit plastischer baustroffe and die festigkeit von schneiden. Z. Angew. Math. Mech. 1, No. 1, 15-20.

Rubin, M. B. \& Einav, I. (2011). A large deformation breakage model of granular materials including porosity and inelastic distortional deformation rate. Int. J. Engng Sci. 49, No. 10, $1151-1169$.

Russell, A. R. \& Khalili, N. (2002). Drained cavity expansion in sands exhibiting particle crushing. Int. J. Numer. Analyt. Methods Geomech. 26, No. 4, 323-340.

Sammis, C. G., Osborne, R. H., Anderson, J. L., Banerdt, M. \& White, P. (1986). Self-similar cataclasis in the formation of fault gouge. Pure Appl. Geophys. 124, No. 1-2, 53-78.

Sheng, D., Eigenbrod, K. \& Wriggers, P. (2005). Finite element analysis of pile installation using large-slip frictional contact. Comput. Geotech. 32, No. 1, 17-26.

Terzaghi, K. (1943). Theoretical soil mechanics. New York, NY, USA: Wiley.

Turcotte, D. L. (1986). Fractals and fragmentation. J. Geophys. Res. 91, No. B2, 1921-1926.

Vesic, A. S. (1973a). On penetration resistance and bearing capacity of piles in sand. Proc. 8th Int. Conf. Soil Mech. Found. Engng, Moscow, 78-81.

Vesic, A. S. (1973b). Analysis of ultimate loads of shallow foundations. J. Soil Mech. Found. Div. ASCE 99, No. 1, 45-73.

Vesic, A. S. (1975). Principles of pile foundation design, Soil mechanics series No. 38. Durham, NC, USA: School of Engineering, Duke University.

Viggiani, G. \& Atkinson, J. H. (1995). Stiffness of fine-grained soils at very small strains. Géotechnique 45, No. 2, 249-265, http://dx.doi.org/10.1680/geot.1995.45.2.249.

Yamamoto, N., Randolph, M. F. \& Einav, I. (2009). A numerical study of the effect of foundation size for a wide range of sands. J. Geotech. Geoenviron. Engng 135, No. 1, 37-45.

Yang, Z. X., Jardine, R. J., Zhu, B. T., Foray, P. \& Tsuha, C. H. C. (2010). Sand grain crushing and interface shearing during displacement pile installation in sand. Géotechnique 60, No. 6, 469-482, http://dx.doi.org/10.1680/geot.2010.60.6.469.

Yasufuku, N. \& Hyde, A. F. L. (1995). Pile end-bearing capacity in crushable sands. Géotechnique 45, No. 4, 663-676, http:// dx.doi.org/10.1680/geot.1995.45.4.663.

Yu, H.-S. (2000). Cavity expansion methods in geomechanics. Dordrecht, the Netherlands: Kluwer Academic.

Zhang, C. S., Nguyen, G. D. \& Einav, I. (2010). Steady state permeability profiles surrounding penetrating piles in crushable granular media. Proceedings of the international symposium on geomechanics and geotechnics: from micro to macro, Shanghai, pp. 789-795. 